\title{
Differences in foraging behaviour between water shrews: Neomys anomalus and Neomys fodiens*
}

\author{
Leszek RYCHLIK
}

Rychlik L. 1997. Differences in foraging behaviour between water shrews: Neomys anomalus and Neomys fodiens. Acta Theriologica 42: 351-386.

The modes and efficiency of foraging in the terrestrial and aquatic habitats in water shrews Neomys anomalus Cabrera, 1907 and $N$. fodiens (Pennant, 1771) were compared in order to investigate if these species can avoid competition for food when they occur syntopically. Seven individuals of $N$. anomalus and five of $N$. fodiens, caught in the Bialowieża Primeval Forest, were tested individually in the terrarium of size $3 \times 0.5 \mathrm{~m}$, containing a $0.25-\mathrm{m}$-wide 'stream' with flowing water of an average depth $25 \mathrm{~cm}$. Six experimental variants, simulating different habitat conditions, were established. Each animal was tested in a given variant during 3 succeeding days for $6 \mathrm{~h}$ a day. In total, $738 \mathrm{~h}$ of shrews' behaviour were recorded in darkness using 2 infra-red sensitive video-cameras. Results obtained on four $N$. fodiens tested with similar methods (648 h; Ruthardt 1990) were included for comparison. $N$. anomalus swam and dived significantly shorter than $N$ fodiens, and they did not take food under water, even when there was no food on land. $N$. fodiens found and took food placed under water and foraged quite efficiently here. They found on average $17.7 \%$ of food portions placed under water in the most similar to natural conditions and $19.4 \%$ when there was no food on land. In both species foraging time on land was much longer than in water. The presence of natural structures increased duration and efficiency of foraging, but this influence was stronger in $N$, anomalus than in $N$. fodiens. These results and literature data suggest that in the wild: (1) both species forage in shallow water and in muddy grounds of wet habitats (wading foraging mode), and also in drier terrestrial habitats (epigeal and hypogeal foraging); (2) only $N$. fodiens forage in deep water (aquatic foraging); (3) the competition for food between $N$. anomalus and $N$. fodiens may be very weak, when potential aquatic prey are available.

Mammal Research Institute, Polish Academy of Sciences, 17-230 Bialowieża, Poland; e-mail: lrychlik@bison.zbs.bialowieza.pl

Key words: Neomys, shrews, behaviour, foraging mode, food searching strategy, competition, microhabitat preferences

\section{Introduction}

The Mediterranean water shrew Neomys anomalus Cabrera, 1907 and European water shrew $N$. fodiens (Pennant, 1771) (Soricidae, Insectivora) are adapted to the semiaquatic way of life. Their biology and ecology are very similar.

*The experimental part of the study was done in the Wildlife-Eco-Ethology Research Group of University of Osnabrück, Germany. 
Both shrew species inhabit banks of running and stagnant waters (both mountain and lowland), marshy meadows, and alder swamps (Dehnel 1950, Pucek 1984, Spitzenberger 1990). Moreover, their sympatric (Dehnel 1950, Borowski and Dehnel 1952, Aulak 1970) and syntopic (Dehnel 1950, Niethammer 1977, 1978, Spitzenberger 1980, Krystufek and Petkovski 1989) co-existence was repeatedly reported. Thus, similarly to other syntopic shrews (Croin Michielsen 1966, Hawes 1977, French 1984, Neet 1989, Kirkland 1991), these two species may compete for both life space and food resources at places of their co-existence.

In the shrew communities the differentiation of trophic niches is usually based on differences in body size (which cause the differentiation of diets as to size of preys), differences in morphological adaptations and microhabitat selection (Kirkland and Van Deusen 1979, Saarikko 1989, Neet and Hausser 1990, Kirkland 1991, Fox and Kirkland 1992, Churchfield and Sheftel 1994, Sheftel 1994). The average body mass of $N$. fodiens is $16.4 \mathrm{~g}$, and that of $N$. anomalus is $10.9 \mathrm{~g}$ (Innes 1994). Such a difference in body size suggests greater abilities of $N$. fodiens to root in soil or hunt large prey, and stronger abilities of $N$. anomalus to climb plants and other objects. Better morphological adaptations to the semiaquatic way of life in $N$. fodiens than in $N$. anomalus (Pucek 1984, Spitzenberger 1990) suggest better abilities of $N$. fodiens to swim and dive. Certain interspecific differences in foraging mode and microhabitat of foraging are predicted therefore. Though most Soricidae investigated up to now are insectivorous generalists (Churchfield 1990, 1994, Churchfield and Sheftel 1994), these two species may also differ as to their prey preferences. Finally, they may forage during different periods of the day and night. According to Saarikko (1989) each of these mechanisms would diminish the competition for food. In shrews this diminishing lies most frequently in vertical separation of foraging sites (Croin Michielsen 1966, Pernetta 1976a, Grainger and Fairley 1978, Terry 1981, Yoshino and Abe 1984, Ellenbroek 1990, Churchfield 1991, Churchfield and Sheftel 1994). The diet and foraging behaviour are in close connection with one another, because often body size as well as anatomical, physiological and behavioural adaptations of a predator determine which prey and in which habitat they can be caught (eg Churchfield and Sheftel 1994).

Foraging behaviour and food preferences of $N$. fodiens have been investigated for a long time, repeatedly and are relatively well-known. There were many field methods used: (1) observation of animals hunting in the wild (eg Sawyer 1946, Brewster 1966, Schloeth 1980, Illing et al. 1981), (2) examination of so called "feeding trays" with prey remains (Buchalczyk and Pucek 1963, Wolk 1976, Kraft and Pleyer 1978), (3) investigation of stomach and guts contents (Niethammer 1977, 1978, Illing et al. 1981, Kuvikova 1985b, Castién 1995), (4) study of food remains in faeces (Churchfield 1979, 1984, DuPasquier and Cantoni 1992); as well as laboratory methods: (5) observation of captive animals (eg Tupikova 1949, Lorenz 1952, Cranbrook 1959), (6) examination of food preferences in so called "cafeteria tests" (Hawkins and Jewell 1962, Churchfield 1985) and (7) experimental investigations of foraging behaviour (Ruthardt and Schröpfer 1985, 
Ruthardt 1990, Köhler 1993, 1996, Vogel et al., in press). All these studies demonstrate clearly that $N$. fodiens are perfectly adapted to forage under water and that a great part of their trophic niche includes typical aquatic prey.

$N$. anomalus is a species poorly investigated in many respects. Reliable data on its diet, foraging behaviour and microhabitat of foraging are very scarce (Niethammer 1977, 1978, Kuvikova 1985a, 1987, Ramalhinho 1995). Opinions about its feeding on aquatic prey, which are frequently presented in books, are insufficiently evidenced. Niethammer (1978) suggests that $N$. anomalus catch prey from the stream in sites of poor flow. But till now, nobody observed behaviour, sites of foraging in $N$. anomalus or tested their abilities to take food from under water.

Therefore, the aims of this study were to investigate in $N$. anomalus: (1) foraging behaviour and efficiency on land and in water (testing hypothesis 1 : $N$. anomalus forage with low efficiency in deep water); (2) relationships between these aspects of foraging and changes (simulated by different variants of experiment) in food availability and distribution on land and in water, as well as the degree of structural differentiation of a site where shrews search for food; and (3) to compare these aspects of foraging in $N$. anomalus and $N$. fodiens (hypothesis 2: $N$. anomalus forage in deep water much less efficiently than $N$. fodiens).

This study was mainly focused on investigation of the mechanisms which determine the behaviour of the two water shrew species, and less on description of natural behaviour of animals living in the wild. However, it was assumed that on the basis of the results obtained here (objective 4) it would be possible to infer the degree of overlap of the trophic niches of $N$. anomalus and $N$. fodiens in the wild, and thereby, about the intensity of competition between them (hypothesis 3 : interspecific differences in foraging behaviour and microhabitat diminish the competition for food). Therefore, the published data on feeding habits of the two water shrew species were incorporated in this fourth objective.

\section{Material and methods}

Experiments were carried out on $7 N$. anomalus ( 6 males and 1 female) and $5 N$. fodiens ( 3 males and 2 females). Animals were trapped in the Bialowieża Primeval Forest and kept for 2 weeks to 4 months in the laboratory of the Mammal Research Institute PAS (MRI) in Bialowieża. Each shrew was kept in a separate cage and fed ad libitum on minced flesh of the forest bison, cow's milk and water. Next, the animals were transported from Białowieża (Poland) to Osnabrück (Germany). More information on keeping conditions in MRI and transporting of animals are reported by Rychlik (1995).

In Osnabrück, shrews were kept in an indoor animal pavilion. Each shrew was placed in a separate terrarium of size $80 \times 40 \times 40 \mathrm{~cm}$. The bedding of the terrarium was composed of a mixture of sand and soil, in proportion $1: 2$ and of thickness ca $10 \mathrm{~cm}$. This enabled animals to burrow underground tunnels and to keep their fur in good condition. On this bedding, natural litter from deciduous wood, moss, turfs of grass, stones, and cuttings of cotton fibres were placed. In each terrarium there was a basin $(30 \times 20 \times 12 \mathrm{~cm})$ with water $10 \mathrm{~cm}$ deep and 2 nest boxes (flower pots) filled with moss and cotton cuttings. Water in the basins was replaced every 1-2 weeks, and bedding and moss were replaced every 3-4 months, according to dirtiness. The temperature in the animals' 
room was $18-20^{\circ} \mathrm{C}$ and humidity was kept at ca $80 \%$. An artificial light-darkness cycle was maintained automatically with the following schedules: in winter $-14 \mathrm{~h}$ of darkness, $9 \mathrm{~h} \mathrm{of} \mathrm{light,} 0.5 \mathrm{~h}$ of dusk before and $0.5 \mathrm{~h}$ after the light phase; in summer - $10 \mathrm{~h}$ of darkness, $13 \mathrm{~h}$ of light, and two 0.5-hour-periods of dusk between the dark and light phases. The changes from the summer schedule into the winter one (in November) and opposite (in April) were done gradually within 2 weeks, by changing the starting time of the light phase. The dark phase started always at 15.30 .

Shrews were fed ad libitum with the "non-test food". Daily servings consisted of dried invertebrates (commercial food for insectivorous birds "Wald-Vogelfuter") and, served alternately, minced flesh of the forest bison or 1-day-old chickens or juvenile laboratory mice. Cow's milk and water were offered as drink. Every few weeks hard-boiled hens' eggs and every 2-3 months pulp of ox-liver and sea fish were also given. This secured the highest possible diversity of diet. Food and milk were served once a day, usually between 12.00 and 14.00. On days when tests were carried out, the "test food" (see below) collected after the experiment was also given at ca 23.00 . The quantity of the test food given was dependent on how many food portions were left after a given test. Usually, there were 5-10 food portions per each shrew remaining in the animal pavilion.

Before the actual experiments, shrews were used in the piloting tests (Rychlik 1995), during which the non-test food was offered. Data from these tests are not included in the results.

\section{Experimental procedure}

The tests were carried out in the laboratory in temperature from ca $18^{\circ} \mathrm{C}$ in winter to ca $24^{\circ} \mathrm{C}$ in summer. An artificial light-darkness cycle was maintained. The dark phase started always at 15.30 and lasted $10 \mathrm{~h}$ in summer and $14 \mathrm{~h}$ in winter. However, light was also turned on between 22.00 and 22.40 in order to describe the results of foraging and collect the food portions remaining after each test. Each test started at 16.00 , ie in the beginning of increased activity of shrews which occur in evening in the wild (Buchalczyk 1972). The set of two connected, nest and experimental, terraria was used.

The nest terrarium (NT) was a glass container of the size $100 \times 50 \times 90 \mathrm{~cm}$ with an open top (Fig. 1). A mixture of sand and soil, in proportion $1: 2$ and of thickness ca $35 \mathrm{~cm}$ composed the bedding. A half of slit ebonite tube ( $4 \mathrm{~cm}$ diameter, $25 \mathrm{~cm}$ long) was buried at a depth of $\mathrm{ca} 15 \mathrm{~cm}$ and adhered to the front wall. The inside of the tube (adhering to the front wall) was covered from outside with a dark piece of movable cordboard. This allowed observation of animals. The nest box (flower pot filled with moss and cotton cuttings) was placed on the surface. There were a few stones and some cotton cuttings covered with a large piece of bark in the NT. After each test, the non-test food was placed under this cover. There was a slit $(5 \times 35 \mathrm{~cm})$ in the right wall of the NT, which was closed with a removable wooden door. The slit made the passage between the NT and experimental terrarium. A lamp with a bulb of $75 \mathrm{~W}$ was installed above the NT. It was connected to an automatic clock which maintained such a light-darkness schedule as was set during a given period in the animal pavilion (ie it was different in winter and summer).

The experimental terrarium (ET) was a container of the size $300 \times 90 \times 100 \mathrm{~cm}$ with an open top, made of steel, glass and plexiglass (Fig. 1). There were terrestrial and aquatic parts, each 25 cm wide, in the ET. The bedding of the terrestrial part was composed of a mixture of sand and soil of thickness ca $15 \mathrm{~cm}$. Mixture of gravel (diameter of granules $0.2-10 \mathrm{~mm}$ ) and small stones, of thickness from 2 to $20 \mathrm{~cm}$, strewed the bottom of the aquatic part. The bank was made of a vertical concrete wall with many irregularities, asperities and embedded stones, which facilitated shrews to exit from water onto the land. The depth of water was from ca $10 \mathrm{~cm}$ near the NT to ca $28 \mathrm{~cm}$ on the opposite end of the ET. The water was maintained by a pump in constant closed circulation. It flowed with a speed of ca $50 \mathrm{~cm} / \mathrm{min}$ in the direction going away from the NT. Before being re-pumped into the ET, water was filtered because, according to Lorenz (1952), clear water is necessary to keep water shrews' fur in good condition. Using thermostat and warming-cooling aggregate (brand "Colora-Tauchkühler"), water temperature was maintained at ca $15^{\circ} \mathrm{C}$ in all tests. In the aquatic part there were 3 "shallows" made 


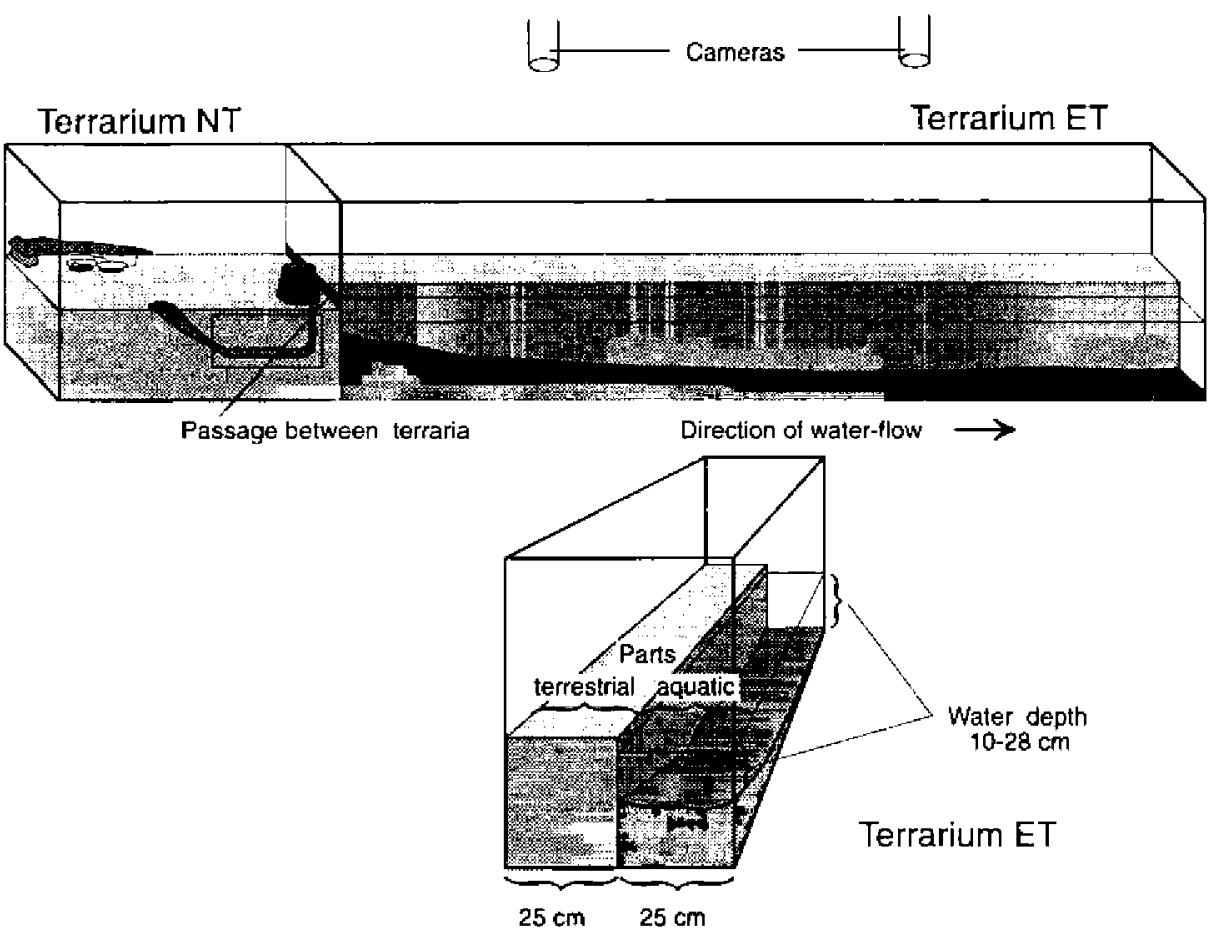

Fig. 1. Schematic diagram of a set of two connected terraria - the nest terrarium (NT) and the experimental terrarium (ET), in which animals were tested.

of ebonite, stone and brick, respectively (Fig. 2). These structures partly protruded from the water, and thereby for shrews, they were suitable places for drinking and starting, stopping or interrupting a swim. In the terrestrial part there were 3 hiding-places made of bark or stones, adhering to the back wall of the ET (Fig. 2). Besides these basic structures, the following natural structures were placed in the ET (in E, D and W experimental variants; see Table 2a); in the terrestrial part - 2 bush roots (instead of the second and third hiding-places), sticks, stones, leaf litter, leaves, and turfs of live grass; in the aquatic part - stones, parts of aquatic plants and pieces of wood as well as the fourth "shallow" (an ebonite shelf hung in half-distance between the second and third "shallows"). The connection between the NT and ET was so wide that the water shrews could enter the ET directly to either the terrestrial or aquatic parts (Fig. 1). The whole of the ET was divided into transverse 10-cm-wide sectors marked outside (Fig. 2).

In all variants, cubes of pig's heart muscle (always new in each test) were given as the test food. One and a half hours before each test the test food was prepared: big (ca $1 \mathrm{~cm}^{3}$ of volume and ca $1.3 \mathrm{~g}$ of weight) and small $\left(0.15 \mathrm{~cm}^{3}\right.$ and $\left.0.2 \mathrm{~g}\right)$ portions of meat. In variants $A, B, E$ (cumulative distribution of food) meat was placed on trays which were sunk into the bedding in such a way that they did not protrude over the surface (Fig. 2). In variants F, D, W (dispersed distribution of food) meat portions were placed directly on the ground of the ET.

Two infra-red sensitive video-cameras of type CCTV Camera WV.BL90 were hung over the ET Their pictures covered the whole $3 \mathrm{~m}$ of the ET with an overlapping zone in the middle. Recording was conducted in darkness, and the ET was illuminated with 2 infra-red-light lamps, each $300 \mathrm{~W}$ of 
Hiding-places

\begin{tabular}{|c|c|c|c|c|c|c|c|c|}
\hline 悹 & 0 & 6 & $x^{3}$ & $\Theta$ & 3 & $\theta$ & 0 & $\theta$ \\
\hline 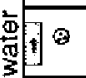 & ${ }^{\circ} \theta$ & $\begin{array}{r}93 \\
0\end{array}$ & & $\theta$ & 3 & & 9 & () \\
\hline
\end{tabular}

Food cumulated on land and in water - variants $A, E, C$, and $G$

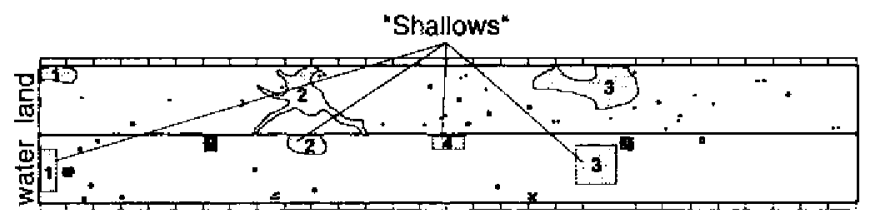

Food randomly dispersed on land and cumulated in water - variants $F$ and D

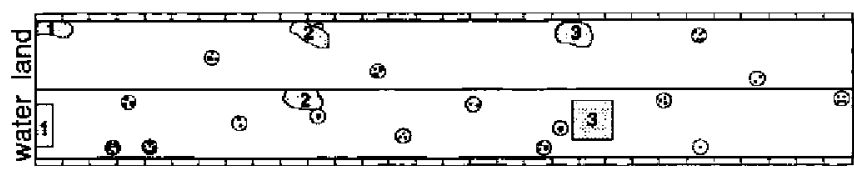

Food cumulated on land and in water, few food on land - variant $B$

$$
\left.\begin{array}{l}
\$ \text { big } \\
A \text { small }
\end{array}\right\} \text { food portions }
$$

Fig. 2. Examples of distribution of big and small food portions, hiding-places, and "shallows" in chosen test variants.

Table 1. Chronology of a single test.

\begin{tabular}{|c|c|}
\hline Time & Manipulations \\
\hline \multirow[t]{2}{*}{15.00} & $\begin{array}{l}\text { 1st day of a test: placement of a shrew and a tray with water (but without food) in the } \\
\text { NT or }\end{array}$ \\
\hline & 2nd and 3rd days: removal of food remaining in the NT, placement of a tray with water. \\
\hline $15.00-15.30$ & Distribution of food portions in the ET. \\
\hline 15.30 & Turning light off in lab; 0.5 h of silence hefore experiment. \\
\hline $15.50-15.58$ & Turning infra-red lamps, video-cameras, and video-recorders on. \\
\hline 15.58 & $\begin{array}{l}\text { Opening of the passage between the NT and ET, start of video-recording, leaving of } \\
\text { the lab by the observer. }\end{array}$ \\
\hline 22.02 & $\begin{array}{l}\text { Turning light on, stop video-recording, placement of a shrew in to the NT, closing of the } \\
\text { passage between terraria. }\end{array}$ \\
\hline $22.05-22.40$ & $\begin{array}{l}\text { Turning video-equipment and infra-red lamps off } \text { counting how many food portions }_{\text {sere handled or taken from a given food-place, how many of them were hoarded in }} \\
\text { hiding-places or abandoned in the ET. }\end{array}$ \\
\hline 22.40 & Feeding a shrew with the non-test food, turning light off. \\
\hline
\end{tabular}


power, which were placed at distance ca $3 \mathrm{~m}$ from the ET. Cameras' image was recorded by 2 video-recorders of type Time Lapse (TL) Panasonic NV-8050.

Each shrew was always tested for 3 days and $6 \mathrm{~h}$ per day in each experimental variant. Table 1 shows the time-table and sequence of manipulations carried on during one test. The period of $6 \mathrm{~h}$ was sufficiently long for shrews to forage several times. The averaging of results from 3 days allowed for the reduction of influences of randomness and intraindividual variation. Results of 3 succeeding days were also used in a study of learning processes in foraging water shrews ( $L$. Rychlik, in prep.). Before testing the next shrew, the ground of two terraria was dug, and structures were either washed (stones, roots, wood) or replaced with new (nest materials, leaves, litter). The surface layer of water was poured off and the loss was filled with tap water. This practice aimed to eliminate as many odour signs from the preceding test as possible. On 3 succeeding days of a given test the total number of big and smalt food portions, as well as sites of their placement (food-points) were not changed. Whereas the number of big and small food portions in a given food-point was changed according to the schedule constant for a given variant. This practice enabled a study of learning processes mentioned above. In total, $612 \mathrm{~h}$ of behaviour of $N$. anomalus in 6 variants and $126 \mathrm{~h}$ of behaviour of $N$. fodiens in 2 variants were recorded

\section{Experimental variants}

In order to study the influence of changes in food availability and habitat structure on foraging of water shrews on land and in water, the following factors were manipulated: (1) placement of food $\rightarrow$ on land or under water, (2) habitat structure $\rightarrow$ natural structures or lack of structures, (3) distribution of food $\rightarrow$ cumulative or randomly dispersed, (4) quantity of food $\rightarrow$ many or few, (5) size of food portions $\rightarrow$ big or small.

Six experimental variants were established (Table 2a; see also Fig. 2). Shrews were tested in the following sequence of variants: A, B, F, E, D, W. The comparison of results obtained in proper variants allowed evaluation of the influence of the following factors: (1) habitat structure $\rightarrow$ by comparison of variants $A$ with $E$ and $F$ with $D$, (2) distribution of food $\rightarrow A$ with $F$ and $E$ with $D$, (3) quantity of food on land $\rightarrow$ A with $B$, (4) quantity of food in water $\rightarrow E$ with $D$. The factors of placement and size of food portions were evaluated in all variants.

Number and biomass of all food portions, numbers of big and small portions, and aggregation indexes in particular variants were chosen according to the field studies of terrestrial and aquatic invertebrates carried out by Ruthardt (1990) as well as some other field studies (Churchfield 1984, 1990, 1993, DuPasquier and Cantoni 1992). The finding that a minimum quantity of insect fond eaten by one $N$. fodiens during $24 \mathrm{~h}$ is $11 \mathrm{~g}$ (Hawkins and Jewell 1962), ie $2.75 \mathrm{~g} / 6 \mathrm{~h}$, was also useful. The aggregation index was calculated according to the formula: DI $=s^{2} / x$, where $x$ is average number of prey (or food portions) in a sample, and $s^{2}$ is variance from $n$ samples (Schwerdteger 1979 cit. in Ruthardt 1990). The higher the DI value, the more cumulated in space the food was.

\section{Analysis of the data recorded on video-tapes}

Video-recordings were watched simultaneously on two monitors of high resolution of picture (type Panasonic WV-5410/G). Behaviour of animals was described with accuracy of $I$ s. Their behaviour was classified into 11 categories, distinguished from the point of view of foraging, as follows: FOOD FIND - visiting a food-point (even if the shrew only passed it); RESTING in NT - stay in the NT (when $>30 \mathrm{~s}$ ); HIDING-PLACE - stay at a hiding-place ( $>30 \mathrm{~s}$ ); LAND - foraging on the terrestrial part of the ET ( $>1 \mathrm{~s}$ ) and stay in the NT ( $<30 \mathrm{~s}$ ), foraging and exploring were considered jointly because the precise distinction between these two behaviours of close biological functions was impossible; SWIMMING - swimming on the water surface ( $>1 \mathrm{~s}$ ); DIVING - swimming under water $(>1 \mathrm{~s})$; BEFORE WATER - short stays on the "shallows" or terrestrial part during foraging in water: short rests, choosing of starting place for diving, etc. (10-30 s); ROOTING in SOIL - rooting in the bedding 
Table 2. (a) Characleristics of experimental variants.

\begin{tabular}{|c|c|c|c|c|c|c|c|c|}
\hline \multirow[t]{2}{*}{ Variant } & \multirow{2}{*}{$\begin{array}{l}\text { Part of } \\
\text { terra- } \\
\text { rium }\end{array}$} & \multirow{2}{*}{$\begin{array}{l}\text { Natural } \\
\text { structures }\end{array}$} & \multicolumn{5}{|c|}{ Food portions } & \multirow[t]{2}{*}{ Pictogram } \\
\hline & & & $\begin{array}{l}\text { Number } \\
\text { (small/big) }\end{array}$ & $\begin{array}{c}\text { Mass } \\
(\mathrm{g})\end{array}$ & Ratio & Distribution & $\begin{array}{c}\text { Aggregation } \\
\text { index }\end{array}$ & \\
\hline \multirow{2}{*}{ A } & L (terestrial) & lack & $36(28 / 8)$ & 16.0 & 1 & cumulative & 3.7 & $\approx$ \\
\hline & $W$ (aquatic) & lack & $36(28 / 8)$ & 16.0 & 1 & cumulative & 3.7 & \\
\hline \multirow{2}{*}{ B } & $\mathrm{L}$ & lack & $13(10 / 3)$ & 5.9 & 1 & cumulative & 2.4 & \\
\hline & $w$ & lack & $36(28 / 8)$ & 16.0 & 28 & cumulative & 3.7 & 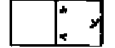 \\
\hline \multirow{2}{*}{$F$} & $\mathbf{L}$ & lack & $38(30 / 8)$ & 16.4 & 1 & dispersed & 1.3 & \\
\hline & $w$ & lack & $38(30 / 8)$ & 16.4 & 1 & cumulative & 5.6 & $\mathbf{y}$ \\
\hline \multirow{2}{*}{$E$} & $\mathbf{L}$ & present & $36(28 / 8)$ & 16.0 & 1 & comulative & 3.7 & \\
\hline & $w$ & present & $36(28 / 8)$ & 16.0 & 1 & cumulative & 3.7 & $04: *$ \\
\hline \multirow{2}{*}{$\mathrm{D}$} & $\mathbf{L}$ & present & $38(30 / 8)$ & 16.4 & 1 & dispersed & 1.3 & \\
\hline & $w$ & present & $68(60 / 8)$ & 22.4 & 1.8 & cumulative & 11.3 & $68=$ \\
\hline \multirow{2}{*}{$w$} & $\mathrm{~L}$ & lack & 0 & 0 & & - & - & \\
\hline & $w$ & $\overline{\text { present }}$ & $68(60 / 8)$ & $\overline{22.4}$ & - & $\overline{\text { cumulative }}$ & $\overline{11.3}$ & $69^{6}$ \\
\hline
\end{tabular}

(b) Characteristics of three additional variants in which only $N$. fodiens were tested by Ruthardı (1990).

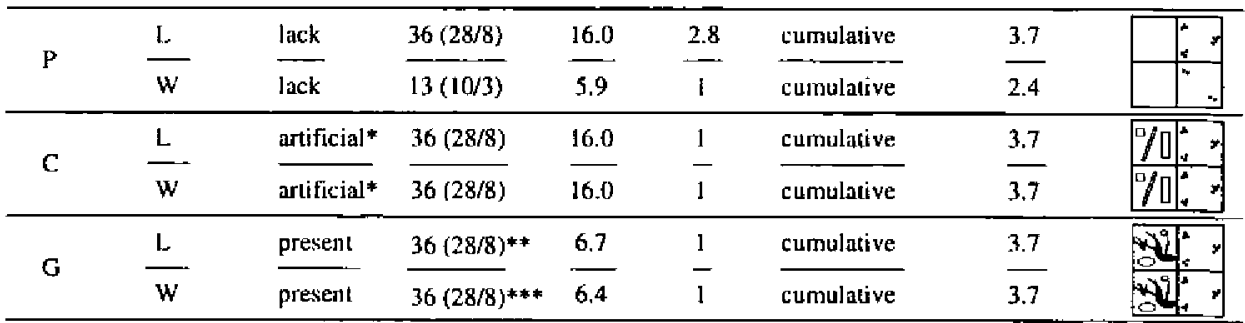

* wooden planks. blocks, sticks and hoods, ** larvae of Tenebrio molior as small prey and Lumbricus sp. as big. *** Cammarks sp. as small prey and Limnea stagnalis as big.

Explanation to pictograms:

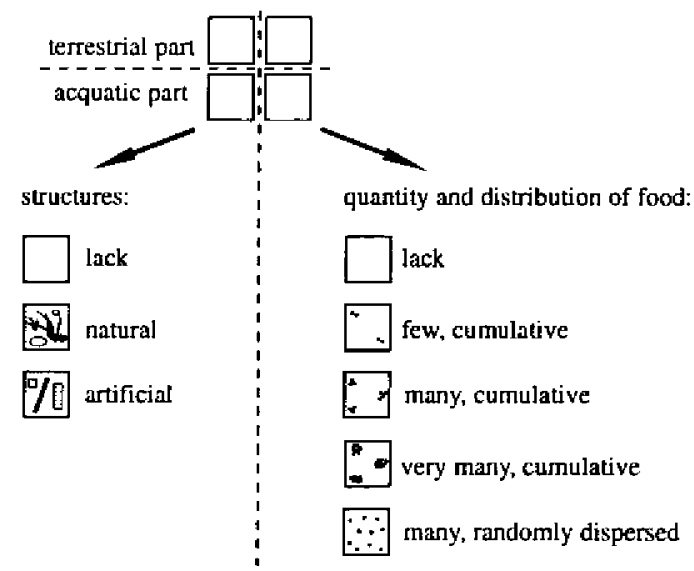


of the terrestrial part ( $>20 \mathrm{~s}$ ); ROOTING in GRASS - rooting in the grass turfs $(>20 \mathrm{~s}$ ); RETRIEVING - collecting and retrieving to nest or a hiding-place a food portion which was earlier found but left in other hiding-place or somewhere in the ET out of a food-point (>1 s); OTHER - other behaviours different from mentioned above ( $>10 \mathrm{~s}$ ).

The food finding was scored as successful when the shrew took or manipulated big or small food portions, and as lack of success when the shrew neither took nor manipulated any food portion. A lack of success was scored also when the shrew visited an empty food-point, ie food-point from which all food portions were already taken.

\section{Data of Ruthardt (1990)}

In this study the processed data taken from the paper by Ruthardt (1990) were used in order to obtain a more complete picture of interspecific differences. In her tests on 4 individuals of $N$. fodiens, Ruthardt maintained the same procedural conditions with the following exceptions: (1) in most variants (except B and P) $N$. fodiens were tested not for 3 days, but for 4 days and 6 h per day; (2) after each test animals were brought back to their terraria in the animal pavilion, and not kept in the NT for 3 days; (3) $N$. fodiens were tested in different sequence of variants: A, B, D, E and F; (4) shrews were additionally tested in variants $P$ and $C$ (see Table $2 b$ for characteristics of these additional variants) between testing in variants $B$ and $D$, as well as in variant $G$ at the end of experiment; (5) in variants $D$ and $G$ instead of cubes of pig's heart muscle, live invertebrates were used: Lymnaea stagnalis (as big prey) and Gammarus sp. (small) in water; Lumbricus sp. (big) and larvae of Tenebrio molitor (small) on land.

\section{Organization and analysis of data}

The computer program "Martmenu" (Ruthardt 1990), used for calculations, produced summarized results obtained in one 6-hour-test. Next, all results obtained for $N$. anomalus (with an exception of distribution of success in time; Fig. 7) were standardized in order to reduce inter- and intraindividual variation. The value obtained for a given shrew on a given day of test in variant $D$ (ie variant of conditions most similar to natural) was assumed as 100 . For example, if total duration of foraging on land of shrew A2 on third day of testing in variant A was $653 \mathrm{~s}$, and duration of foraging on land of the same shrew on third day in variant $D$ was $1399 \mathrm{~s}$, then the value of variant $D$ was assumed as 100, and for variant $A$ : $(653: 1399) \times 100=46.68$. When the value of any variable in variant $D$ was 0 (as eg total duration of foraging under water or number of food portions found under water), then 0 was replaced with 1 in order to make the calculation performable.

Next, for each animal tested in a given variant, the three standardized values of three succeeding days were averaged. These averages were treated as trials of samples compared statistically in order to evaluate inter-variant differences. Of course, in variant $D$ all standardized values equaled 100 , and standard deviations calculated from them equaled 0 .

In the statistical comparison of results obtained for $N$. anomalus and $N$. fodiens the standardization of results was impossible. Here, for each shrew tested in a given variant, the real values from 3 succeeding days were averaged and these averages (averages of first degree, $1^{\circ}$ ) were treated as trials in statistical tests. Results concerning distribution of foraging success in time (Fig. 7) were compared by Kolmogorov-Smirnov test, and remaining results - by Wilcozon test (Greń 1982, SYSTAT V5 1992).

In most figures averages of $2^{*}$ and standard deviations, calculated from averages of $1^{*}$ of real values, are shown. In the figures $n$ means number of shrews tested in a given variant. For example, in variant $A$ duration of time spent by seven $N$. anomalus in the terrarium ET were (on average for 3 days): $1995.3,934.7,4336.0,328.0,751.3,2015.0$ and $2166.3 \mathrm{~s}$ (these are averages of $1^{\circ}$ ). For these 7 values the average is 1789.5 (this is average of $2^{\circ}$ ) and standard deviation is 1333.2 . These two final values are shown in Fig. 3: Terrarium ET. 
Neomys anomalus Neomys fodiens
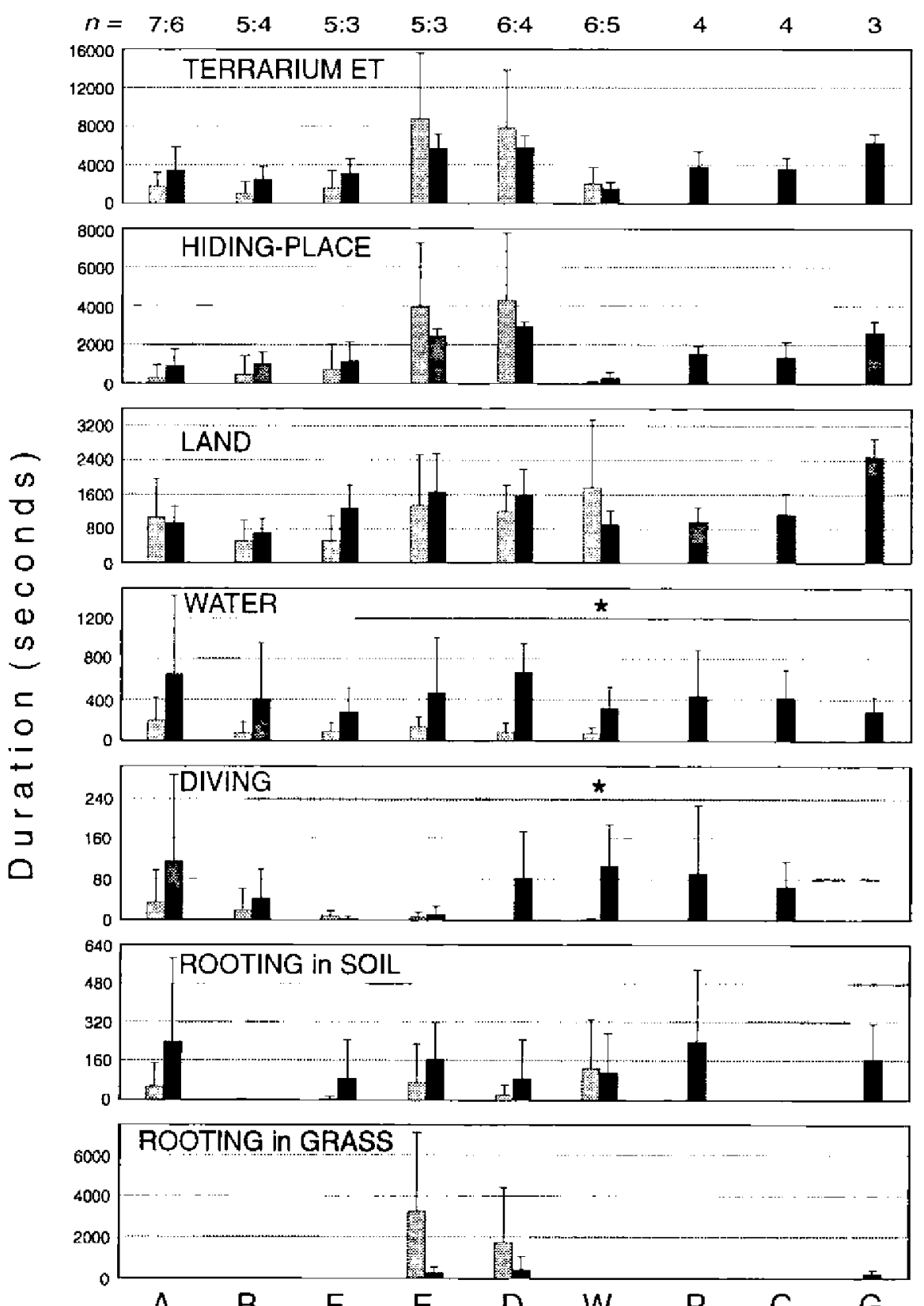

$\begin{array}{lllllllll}A & B & F & E & D & W & P & C & G\end{array}$

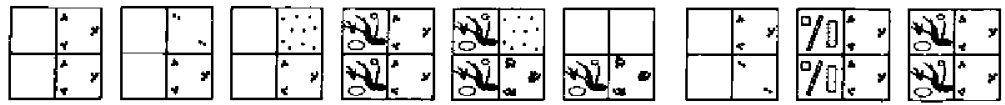

Variants 


\section{Results}

\section{Foraging of Neomys anomalus}

Foraging behaviour

Presence of natural structures (variants $\mathrm{E}$ and $\mathrm{D}$ ) caused $N$. anomalus to spend significantly more time in the terrarium ET than in variants without natural structures (A, B, F, and W) (Wilcoxon test: $Z=2.02$ to $2.20, p<0.05$ ). Shrews mainly stayed in hiding-places (Fig. 3). Time spent in hiding-places was also significantly longer in variants $\mathrm{E}$ and $\mathrm{D}$ than in $\mathrm{A}, \mathrm{B}, \mathrm{F}$, and $\mathrm{W}(Z=1.99$ to 2.23, $p<0.05$ ), with an exception of difference between $\mathrm{E}$ and $\mathrm{F}$. Duration of foraging on land and rooting in soil increased then too, especially in variant $E$, in which duration of foraging on land was significantly longer than in variant $\mathrm{F}(Z=2.02$, $p<0.05$ ). On the other hand, in the presence of natural structures, duration of foraging under water decreased considerably (in variants $E$ and $D$ it was significantly shorter than in $\mathrm{A} ; Z=2.03$ and 2.02 respectively, $p<0.05) . N$. anomalus did not dive at all under most natural conditions of variant $D$.

In contrast to cumulative distribution, random dispersion of food portions on land (comparison of variants $\mathrm{A}$ with $\mathrm{F}$ and $\mathrm{E}$ with $\mathrm{D}$ ) caused little increase of time spent by $N$. anomalus in hiding-places and little decrease of duration of other behaviours. Though this tendency is statistically insignificant, it is visible regardless of the presence (variants $E$ and $D$ ) or lack (variants $A$ and $F$ ) of natural structures.

Double quantity of food under water (in variant $\mathrm{D}$ in relation to variant $\mathrm{E}$ ) did not cause a significant change in duration of foraging in water or under water. Great decrease of the number of food portions on land, but with maintenance of other experimental conditions (comparison of variants A with B), did not cause intensification of any activity. In contrary, this caused slight decreases of their durations (only duration of foraging under water was significantly shorter in variant $\mathrm{B}$ than in $\mathrm{A} ; Z=2.02, p<0.05$ ).

Results obtained in variant $W$ (food in high quantity, cumulated, but placed only under water) differ from the above picture. Total time spent by $N$, anomalus in the ET in variant W (Fig. 3; Terrarium ET) was longer than in other variants without natural structures, ie A, B, F (difference between variants $W$ and $B$ was

Fig. 3. Comparison between Neomys anomalts and $N$. fodiens of average durations of the different behaviours. TERRARIUM ET - time spent in the terrarium ET $=$ (duration of the test - duration of RESTING in NT), WATER - foraging in water = (SWIMMING + DIVING + BEFORE WATER). Significant interspecific differences ( $p<0.05$, Wilcoxon test) are marked by asterisks. $n$ - number of animals tested in a given variant, eg 7:6 means that $7 \mathrm{~N}$. anomalus individuals and $6 \mathrm{~N}$. fodiens individuals were tested (in variants $\mathrm{P}, \mathrm{C}$ and $\mathrm{G}$ results only for $N$. fodiens). Standard deviations are shown. See "Analysis of data recorded on video tapes" and Table 2 for more explanations.

Note! In Figs 3-6, variant A shows the average results obtained on $2 N$. fodiens individuals tested during this study and 4 tested by Ruthardt (1990), variant $W$ - on $5 N$. fodiens tested during this study, and the remaining variants - on 3 or $4 N$. fodiens tested by Ruthardt (1990). 
significant; $Z=2.02, p<0.05$ ). At the same time, duration of foraging on land was the longest (difference between variants $W$ and $B$, and $W$ and $F$ were significant; $Z=2.02, p<0.05$ ). Also duration of rooting in soil was the longest in variant $W$. In contrast, time spent in hiding-places was the shortest (differences between variants $\mathrm{W}$ and $\mathrm{E}$, and $\mathrm{W}$ and $\mathrm{D}$ were significant; $Z=2.02$ and 2.23 respectively, $p<0.05$ ). This means that in variant $W N$. anomalus did not linger in hiding-places but they intensified foraging on land. However, they did not intensify foraging in and under water, despite of a high abundance of food placed there.

Total duration of rooting in grass was quite long (ca $1 \mathrm{~h}$ in variant $\mathrm{E}$ and ca $0.5 \mathrm{~h}$ in D; Fig. 3). Sometimes shrews prepared temporal nests in grass and rested there. Although this is included in the activity of rooting in grass, such a result may suggest the natural tendency of $N$. anomalus to searching for food among terrestrial plants and their roots.

In $N$ anomalus rooting in soil consisted almost always in digging of shallow holes. Rarely the holes were so large that the shrew could enter it. But a longer tunnel was never created in the ET.

Foraging success

In all experimental variants $N$. anomalus found no or almost no food portion placed under water, while they foraged on land quite successfully (Fig. 4). Their foraging success on land was higher when natural structures were present in the terrarium ET (variants E and D) than when they were absent (variants $A, B$ and F). All differences were significant (Wilcoxon test: $Z=2.02$ to $2.20, p<0.05$ ), except difference between variants $\mathrm{F}$ and $\mathrm{D}$ (Fig. 4). Success reached $70-80 \%$ of food portions found from all portions placed on land. Cumulative distribution of food (variant E) resulted in lower (though statistically insignificant) success than dispersed distribution (variant D). Under lack of natural structures the opposite tendency was observed: $N$, anomalus found proportionally more food portions when food was cumulated on land $(43.3 \%$ of food portions given in variant $A$ and $41.6 \%$ in $B$ ) than when food was randomly dispersed ( $33.7 \%$ in variant $F$ ) (though these differences were also statistically insignificant). Although the number of food portions given on land was in variant $B$ ca three times lower than in other variants, the percent of food portions found by $N$. anomalus in this variant remained low $(41.6 \%)$.

On land $N$. anomalus always found proportionally more big than small food portions (Fig. 5), with an exception of variant A. These differences were significant in variants $\mathrm{B}, \mathrm{F}$ and $\mathrm{E}$ (Wilcoxon test: $Z=2.02, p<0.05$ ). Whereas, all food portions found by $N$. anomalus under water (in variants $A, F$ and $E$ ) were small. But there were very few of them.

Because $N$. anomalus did not take food under water results of variant W were omitted in further analysis of foraging success. 


\section{Neomys anomalus Neomys fodiens}

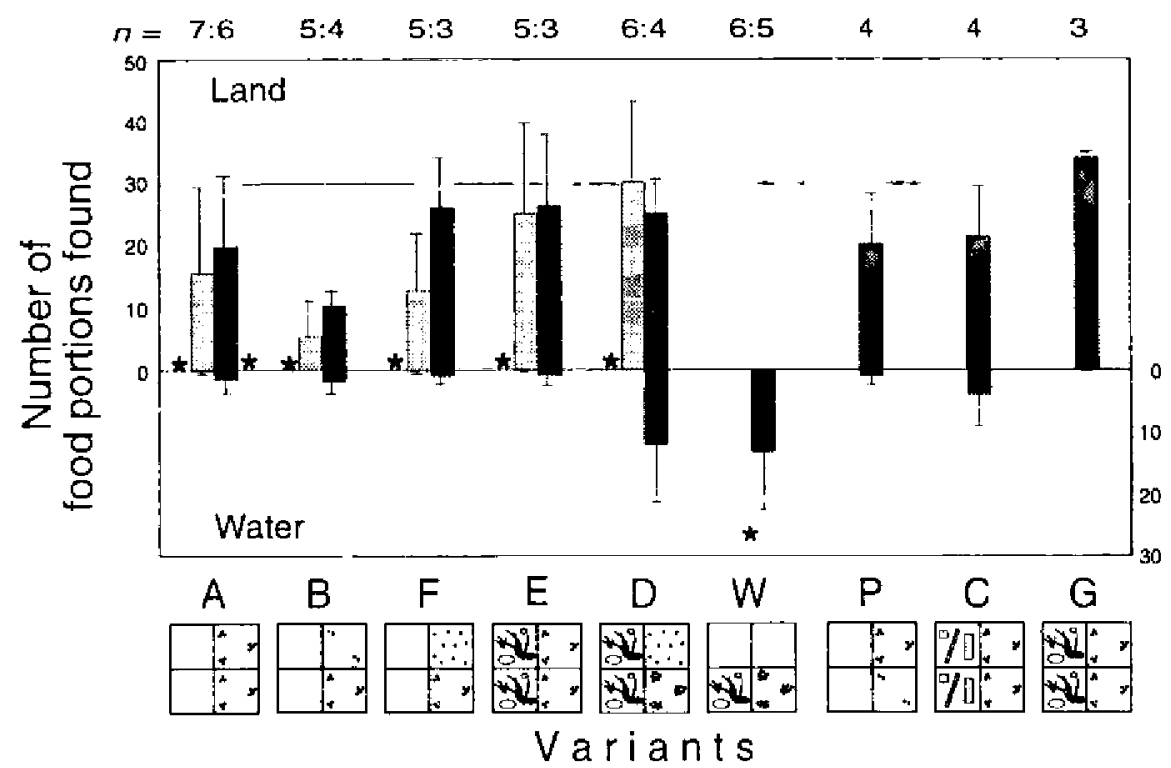

Fig. 4. Foraging success of Neomys anomalus and $N$. fodiens, expressed as an average number of food portions found, separately for the terrestrial (Land) and aquatic (Water) parts of the ET. Significant differences ( $p<0.05$, Wilcoxon test) were marked by asterisks: An asterisk placed on the left side of the bar means a difference between foraging suecess in land and water in $N$. anomalus. An asterisk placed on the right side means the same difference in $N$. fodiens. In variant $W$, an asterisk under a bar means a significant interspecific difference. See Fig. 3 for more explanations.

In $N$. anomalus foraging efficiency was the highest (ie time needed to find 1 food portion was the shortest; Fig. 6) in variant D with most natural conditions, and it was the lowest when there were few, cumulated food items on land and no natural structures (variant $B$ ).

Generally, foraging efficiency was higher in the presence of natural structures (variants $\mathrm{E}$ and $\mathrm{D}$ ) than in their absence (variants $\mathrm{A}, \mathrm{B}$ and $\mathrm{F}$ ). Differences were significant between $\mathrm{D}$ and $\mathrm{B}, \mathrm{D}$ and $\mathrm{F}$, and $\mathrm{E}$ and $\mathrm{B}$ (Wilcoxon test: $Z=2.02$, $p<0.05$ ). The distribution of food also had an important influence on foraging efficiency because, both in presence (variants $E$ and $D$ ) and absence (variants A, $B$ and $F$ ) of natural structures, the foraging efficiency was significantly higher when food on land was dispersed, ie in variants $\mathrm{F}$ and $\mathrm{D}(Z=2.02$ and $p<0.05$ for differences between $E$ and $D$, and $B$ and $F$ ). The lack of a significant difference between variants A and B (Fig. 6) suggests that the total quantity of food on land had no decisive influence on foraging efficiency. Thus, foraging efficiency of $N$. anomalus was first of all influenced by food distribution, and next by presence or lack of natural structures. 


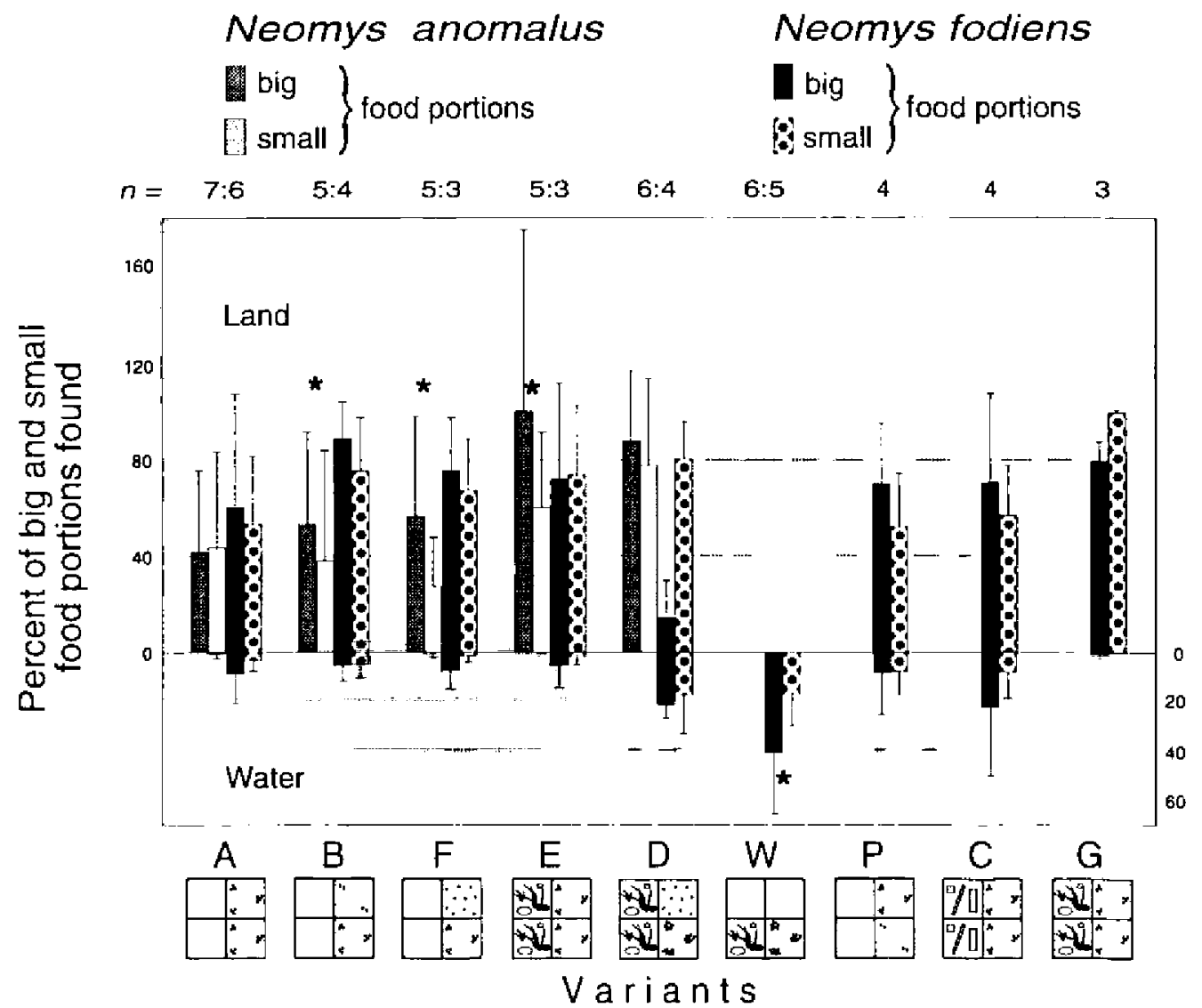

Fig. 5. Percentage-ratio of the average number of big and small food portions found by Neomys anomalus and $N$. fodiens to the number of food portions placed in the terrarium ET, separately for the terrestrial (Land) and aquatic (Water) parts. Significant interspecific differences $(p<0.05$ Wilcoxon test) between the percentage of big vs small food portions found were marked by asterisks. Note! A food portion found, but not taken immediately from the given food-point, could be found again in what was classified as another success. Therefore, total success could exceed $100 \%$ as is indicated by the height of standard deviations. See Fig. 3 for more explanations.

Distributions of $N$. anomalus foraging success in time of 24 quarters of test duration as well as in three 2-hour-periods were compared in Fig. 7. The time was recorded starting from the first entrance to the ET by each shrew. Foraging success in each succeeding quarter is presented as percentage of the total number of food portions found during all quarters in a given variant.

In all 5 variants $N$. anomalus found most food during the first quarter after entering the terrarium ET. This indicates that presence or lack of natural structures as well as changes in distribution and quantity of food given to them did not hinder their foraging and defer the first finding of food. In subsequent 
Neomys anomalus Neomys fodiens

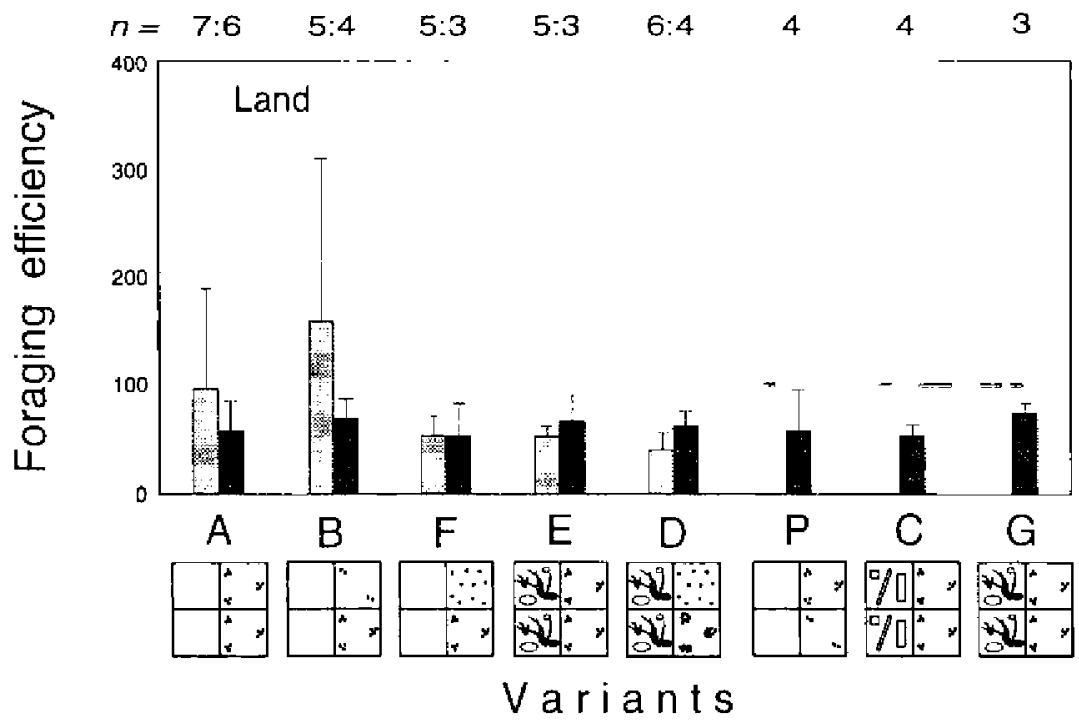

Fig. 6. Foraging efficiency on land of Neomys anomalus and $N$. fodiens, expressed as time needed to find 1 food portion (ie ratio of foraging time on land to number of food portions found on the terrestrial part of the ET). See Fig. 3 for more explanations.

quarters shrews found successively fewer food portions. Hence, they usually found most of the food in the first 2-hour-period of foraging and least in the third period. Differences between variants in distributions of foraging success during 24 quarters were not significant (Kolmogorov-Smirnov test: $p>0.05$ ). However, in variants with natural structures ( $E$ and $D$ ) shrews found food more steadily in time, whereas in variants without structures (A, B and F) most of all at the beginning of foraging. The distribution of food did not influence the success distribution during 24 quarters of foraging by $N$. anomalus (differences between variants $A$ and $F$, and $E$ and $D$ are insignificant). The reduction of food quantity on land, with other conditions unchanged, also did not cause significant change in the success distribution in time, accessed in the whole foraging period (difference between variants $B$ and $A$ was insignificant).

However, some differences between variants were significant when distributions of success in time were compared in three 2-hour-periods:

(1) In the 1st period, the success distribution in variant $B$ ( $\mathrm{few}$ and cumulated food, lack of structures) was significantly different (Kolmogorov-Smirnov test: $D=0.63, p<0.05$ ) from variant $\mathrm{E}$ (many and cumulated food, natural structures). This difference is due to fact that in variant $B$ shrews found lots of food during the first quarter, and few during next seven quarters, whereas in variant $E$ the difference between the first and next seven quarters was low. 


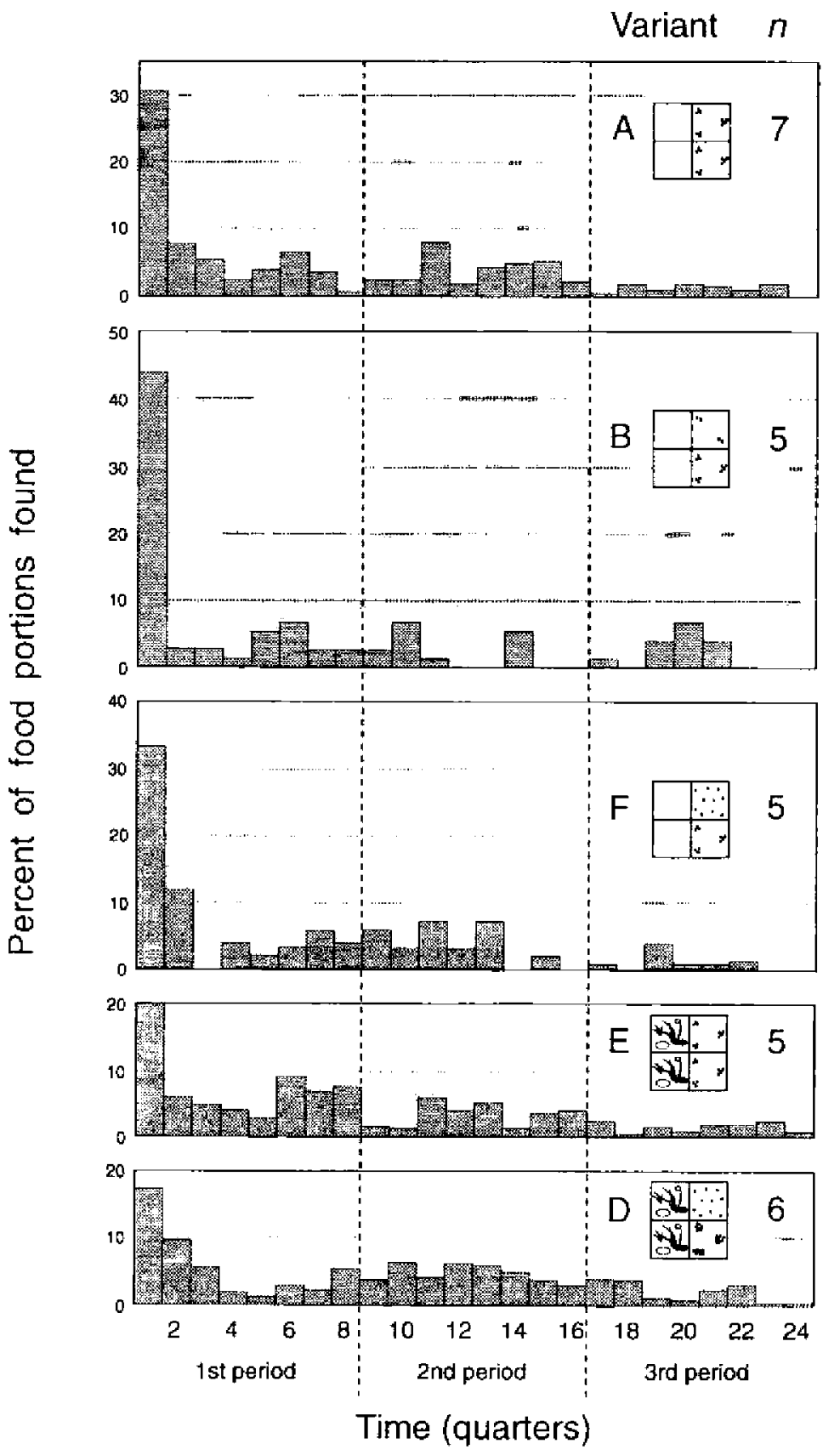

Fig. 7. Distribution of $N$. anomalus foraging success in time, displayed as a percentage of fond portions found in given quarters compared to the number of all food portions found in a given variant. Time was measured in quarters, starting with the first animals' entrance to the ET. Vertical dashed lines divide time of foraging into three 2-hour periods. 
(2) In the 2nd period, the success distribution in variant B was significantly different from variants A (many and cumulated food, lack of structures; $D=0.63$, $p<0.05$ ) and $D$ (many and randomly dispersed food, natural structures; $D=0.75$, $p<0.01$ ). In the 2 nd period $N$. anomalus found less food in variant B than in variants $A$ and $D$.

(3) In the 3rd period, the success distribution in variant $F$ (many and dispersed food, lack of structures) was significantly different from variant $E$ (many and cumulated food, natural structures; $D=0.63, p<0.05$ ). In the $3 r$ period shrews found less food in variant $F$ than in variant $E$ (Fig. 7).

Thus, distribution in time of foraging success in $N$. anomalus was significantly influenced by quantity of food portions given on land. Under low quantity, most of them were found during the first phase of foraging. The presence of natural structures was also important because they lead to $N$. anomalus finding many food portions also during the 2 nd and 3 rd periods of foraging. The food distribution did not significantly influence the distribution in time of foraging success.

\section{Recapitulation}

(1) $N$. anomalus did not take food placed $>10 \mathrm{~cm}$ under water, although they swam and dived. When there was no food on land, N. anomalus intensified foraging on land but not foraging in water. They always foraged longer on land than in water. Under water they foraged very briefly. These results indicate a very poor ability of $N$. anomalus to forage in deep water.

(2) The presence of natural structures caused prolongation of duration of most behaviours on land and increased foraging success and efficiency.

(3) The distribution of food on land also influenced duration of some behaviours and foraging efficiency of $N$. anomalus. Random dispersion of food (which simulated the natural situation) caused increase of foraging efficiency.

(4) Reduction of food quantity on land shortened duration of foraging and other behaviours as well as decreased foraging success.

(5) N. anomalus found proportionally more big than small food portions.

$$
\text { Comparison of foraging in Neomys anomalus and Neomys fodiens }
$$

With the exception of variants $\mathrm{A}$ and $\mathrm{W}$, the number of $N$. fodiens individuals tested was too small ( 3 or 4 ) for interspecific differences to be statistically significant.

Foraging behaviour

In all variants (except $\mathrm{F}$ ), $N$. fodiens foraged in and under water longer than $N$. anomalus (Fig. 3 ). In variant $\mathrm{W}$ these differences were significant (Wilcoxon test: $Z=2.02, p<0.05$ ). This means that foraging in and under water were not only forced by the lack of food on land (in variant $\mathrm{W}$ ), but $N$. fodiens displayed such a tendency under all experimental conditions. This is especially true for 
variant $\mathrm{D}$ with most natural conditions. In contrast, $N$. anomalus did not forage under water at all in variant $D$.

$N$. fodiens spent a short time on rooting in grass in all three variants ( $\mathrm{E}, \mathrm{D}$ and $G$ ), whereas $N$. anomalus rooted in grass considerably longer in both variants $\mathrm{E}$ and D. In $N$. fodiens results obtained in variants with natural structures differ little from results obtained under lack of structures. This is true for most categories of behaviour. Whereas in $N$. anomalus such differences are clear. This allows to conclude that $N$. fodiens is less influenced by structural changes in environment than is $N$. anomalus.

$N$. fodiens rooted in soil more than $N$. anomalus. Though the differences were insignificant statistically (too small sample size for $N$. fodiens), the tendency is visible in all variants, except $B, W$ and $C$.

In both shrew species and in all variants, duration of foraging on land was longer than in water (Fig. 3). However, if proportion of duration of foraging on land to duration of foraging in water in $N$. fodiens was (on average for 9 variants) ca 3.3 (from 1.4 in variant A to 8.7 in $G$ ), the same proportion in $N$. anomalus was (on average for 6 variants) as high as 10.5 (from 5.3 in $A$ to 22.0 in W). The difference between average proportions is significant (Wilcoxon test: $Z=2.02$, $p<0.03$ ). This indicates that the preference to forage on land is stronger in $N$. anomalus than in $N$. fodiens.

\section{Foraging success}

The differences in behaviour had their reflection in differences in foraging success (Fig. 4). First, in all variants $N$. fodiens found more food under water than $N$. anomalus. This difference is especially clear in variant $W$ (no food on land; Wilcoxon test: $Z=2.20, p<0.05$ ) and in variant D (most natural conditions). $N$. fodiens found, on average, $19.4 \%$ of food portions placed under water in variant W and $17.7 \%$ in D, whereas $N$. anomalus did not find food under water at all in these variants. Second, the presence of natural structures increased the foraging success on land to the higher degree in $N$. anomalus than in $N$. fodiens.

On the other hand, both species found always more food on land than in water. This difference is significant in $N$. anomalus in all variants and in $N$. fodiens in variant $\mathrm{A}(Z=2.02$ to $2.37, p<0.05)$.

Similarly to $N$. anomalus, $N$. fodiens found on land proportionally more big than small food portions (Fig. 5), with an exception of variants with natural structures ( $E, D$ and $G$ ). The results were quite opposite in variants $D$ and $G$, in which instead of pieces of meat, live invertebrates were offered to $N$. fodiens. In these variants earth-worms were given as big prey and meal-worm larvae as small prey. In variants $D$ and $G$ earth-worms (which also in the wild are reluctantly eaten by $N$. fodiens - eg Churchfield 1985) were taken proportionally less frequently than meal-worm larvae. Thus, not size but quality of prey could influence these results. In variant $\mathrm{E}$ (many and cumulated food, natural structures) 
$N$. fodiens found big and small meat portions in equal proportions, whereas $N$. anomalus clearly preferred big portions.

$\Lambda$. fodiens found under water always proportionally more big than small food portions (Fig. 5). This difference is statistically significant in variant $W$ (Wilcoxon test $Z=2.02, p<0.05$ ). Whereas all food portions which $N$. anomalus found under water (variants $A, F$ and $E$ ) were small. But the total number of these food portions was too low to state decisively that the two shrew species display different prefarences as to size of prey caught under water.

In two variants with cumulated food and lack of natural structures (A and B) the foraging efficiency on land was lower in $N$. anomalus than in $N$. fodiens (insignificant differences). In the remaining variants efficiency was similar in the two species (Fig. 6). Thus, is seems that the presence of natural structures did not influence the foraging efficiency of $N$. fodiens as clearly as in $N$. anomalus. On the other hand, similarly as in $N$. anomalus, the foraging efficiency of $N$. fodiens on land tended to be higher when food was randomly dispersed on land (in rariants $\mathrm{F}$ and $\mathrm{D}$ ) than when it was cumulated (remaining variants): under lack of natural structures the efficiency in variant $F$ was higher than in variants $\mathrm{A}, \mathrm{E}$, and $\mathrm{P}$; under presence of natural structures the efficiency in variant $\mathrm{D}$ was higher than in variants $E$ and G. Results of foraging success (Fig. 4) obtained under lack of natural structures are conformable to this tendency: foraging success of $N$ fodiens on land was higher when food was randomly dispersed (variant $F$ ) thar. when food was cumulated on land (variants A, B, P).

$$
\text { Recapitulation }
$$

(-) Rarely did $N$. anomalus find food under water in all 6 variants, whereas $N$. frdiens found and took food under water in 8 from 9 variants. In variant D (most natural conditions) and $\mathrm{W}$ (food only under water) they did this with high efficency.

(a) N. anomalus foraged in and under water less than $N$. fodiens.

(9) In the two species and in all variants, duration and success of foraging on land were considerably longer and higher than in water.

(4) The influence of habitat conditions on foraging behaviour and success was stronger in $N$. anomalus than $N$. fodiens. Presence of natural structures increased forafing success and efficiency.

(6) Both species preferred big over small food portions.

\section{Discussion}

Ir this study the method of laboratory experiment was chosen because: (1) it alloved the exact control of conditions in each repetition of tests; (2) it enabled the easy manipulations of such factors as placement of food, structures in terrarium, distribution, quantity and size of food portions given; (3) video-recording 
secured the repeatable and exact analysis of each event. Similar observations in the wild would be impossible.

High individual variation in behaviour of tested shrews caused high standard deviations to accompany the average results obtained. Statistical insignificance of many (apparently considerable) intra- and interspecific differences corresponds with this fact. The variation could result from different sexes, stages of sexual activity, and duration of keeping in captivity of different animals. High individual variation of shrew behaviour was emphasized by Crowcroft $(1955,1957)$. In a study of foraging behaviour in Sorex araneus, Churchfield (1980) could not carry out the statistical analysis because of intra- and interindividual variation. Due to the same cause, Ruthardt (1990) did not average results but she analyzed the foraging of each $N$. fodiens individual separately. Köhler $(1993,1996)$ also found high individual variation of behaviour and learning abilities in the same species. But on the other hand, many important differences found in my study were statistically significant. Additionally, many of my results display conformable tendencies. This indicates the reliability of the results obtained in this study.

Foraging of Neomys anomalus in the experiment

The present tests proved that $N$. anomalus foraged briefly in and under water and that they did not take food placed $\geq 10 \mathrm{~cm}$ under water surface. However, they foraged long and successfully on land, especially under semi-natural conditions. Similar results were obtained in the group experiment (L. Rychlik, in prep.) in which a group of $4 \mathrm{~N}$. anomalus shrews was placed simultaneously in the set of the NT and the ET terraria and tested in variants A, D and W. Also under these conditions $N$. anomalus did not take any food portion under water, but they took $100 \%$ of food placed on land.

These results are in variance with common opinions (eg Gureev 1971, 1979, Görner and Hackethal 1987) as well as results of Kuvikova (1987) and especially Niethammer $(1977,1978)$, according to which at least part of diet of $N$. anomalus is composed of aquatic animals. Thus, one could suggest that some errors in the method of animal keeping or experimental procedure were committed and they determined such results. However, under the same conditions $N$. fodiens maintained an equally good physical condition and state of fur, they intensively dived and took food placed under water. This means that (1) the way of keeping animals in captivity did not lead to loss of abilities of diving and swimming or cause them to forget underwater foraging; (2) kind and quantity of food as well as conditions and duration of one test $(6 \mathrm{~h})$ were fitted in such a way that animals which possessed the ability to forage in deep water displayed this ability. Therefore, it seems that methods of this study were well-chosen and results obtained are a reliable reflection of foraging of $N$. anomalus. Hence, these results suggest that in the wild $N$. anomalus really do not forage under water, at least not at depth of more than $10 \mathrm{~cm}$. 
N. anomalus successfully foraged on land and displayed a strong tendency to root in soil and grass. Yoshino and Abe (1984) distinguished in shrews two modes of rooting: (1) surface digging for prey being shallow deep in the ground by shrews remaining on the surface, (2) burrowing for prey which are deep in the soil. In the present study, the behaviour similar to the first mode was observed in $N$, anomalus that suggests that they are able to find food in this way also in the wild. According to Churchfield and Sheftel (1994), in shrews the ability to such a foraging mode increases with size of their body: among 8 species of shrews co-existing on the River Yenisei, the largest Sorex roboratus (13.0 g) and $S$. isodon. $(13.5 \mathrm{~g})$ dug out food from soil in the highest proportion. $N$. anomalus are large enough (mean body mass $10.9 \mathrm{~g}$ - Innes 1994; maximum $20.4 \mathrm{~g}$ - Pucek 1984) to get food in this way too, at least by surface digging. On the other hand, deep burrowing may not be advantageous because most soil invertebrates live in the top $5 \mathrm{~cm}$ of soil, as it was found for different habitats of the Siberian taiga (Churchfield et al. 1997). However, small Sorex minutus, observed in captivity, burrowed corridors rarely, whereas larger $S$. araneus, S. caecutiens and S. vir burrowed frequently and efficiently (Yudin 1962).

Rooting in grass was sometimes a sign of nest building behaviour because the preparation of temporary shelters in turfs of grass in the ET, and resting in them, were observed in $N$. anomalus. But frequent taking of food placed in grass and prolonged rooting of $N$. anomalus in the under parts of grass turfs were also observed. This suggests that in nature $N$. anomalus may forage among lower parts of plants as roots and dead blades of grasses and sedges. These sites are frequently inhabited by different invertebrates in great number (Churchfield 1993).

Considering diets, habitat use, and the degree of anatomical and physiological adaptations, four main foraging modes were distinguished so far in shrews: epigeal, hypogeal, aquatic, and scansorial (Hutterer 1985, Churchfield 1990). Many, especially temperate-zone shrews use two or more foraging modes (Churchfield 1990, 1994). Next, regarding body sizes of shrews and their prey, Churchfield and Sheftel (1994) divide Sorex shrews (foraging epi- and hypogeally) in 3 functional groups: (1) large shrews hunting mainly on large prey by digging out them from soil and litter, (2) small shrews hunting mainly on small prey exclusively on the ground surface and on plants (shrews of these two groups show a tendency to trophic specialization and their trophic niches overlap to the little degree), (3) medium-size shrews hunting on all prey and in all microhabitats (generalists with high overlap of trophic niches). It seems that $N$. anomalus are large enough to hunt large prey and they can successfully forage in terrestrial microhabitats, also in the way of digging out prey from soil, roots and lower parts of plants. Thus, it can be concluded that $N$. anomalus belong to the first functional group and they forage in epigeal and hypogeal modes.

Kuznetzov (1972) suggested that Crocidura suaveolens can inhabit only areas where their prey are evenly dispersed on the ground surface or in upper layers of soil. Since foraging success in Sorex cinereus and Blarina brevicauda (Holling 
1959) as well as in S. araneus (Churchfield 1980) increased with the increase of density of dispersed prey, Churchfield (1980) concluded that these species search for prey using "random searching pattern". Later, this pattern was proved in $S$. araneus (Pierce 1987). Finally, Churchfield (1990) wrote that all shrews, which forage epigeally, locate their prey in "a process of random but thorough searching" of a patch. In $N$. anomalus foraging success and efficiency on land were almost always higher in variants with randomly dispersed food on land than in those with cumulated food. This suggests that also $N$. anomalus use the random searching pattern during foraging. This strategy of food searching is an adaptation to finding prey dispersed within a patch and to exploiting the food resources dispersed in the environment.

Based on the results of the present study one shöuld state that structural complexity of habitat exerts a great influence on foraging of $N$. anomalus in the wild. This is because, in the presence of natural structures in the E'T, the foraging success and efficiency increased significantly, and duration of some behaviours was prolonged. Though these results seem to be quite obvious, it is difficult to show mechanisms on which they are based.

Churchfield (1993) suggests that shrews are able to learn about spatial distribution and abundance of prey within their home ranges. It was also found that shrews show the tendency to return to the same site if they have already found prey there before (Pernetta 1977, Churchfield 1980, Yoshino and Abe 1984, Köhler 1993, 1996). So, one can suppose that natural structures facilitate the memorization of the way to food clumps previously located. Higher foraging success and efficiency in variant $E$ (cumulated food and natural structures) than in A (cumulated food but lack of structures) support such a supposition. But the equally high foraging efficiency in variant $F$ (dispersed food and lack of structures) as in $\mathrm{E}$ raises doubts. It was shown above that $N$. anomalus probably search for food in randomly chosen sites. During this mode of foraging, the ability to remember the way between some points or of their own position in an area does not seem to be necessary.

However, there are two other mechanisms which could allow natural structures to increase foraging success. First, the rich structural differentiation of habitat may produce a stronger internal motivation, or may be a stronger external releaser for exploratory behaviour than the simple habitat. In variants with natural structures (E and $\mathrm{D}$ ) the conditions were probably so attractive that $N$. anomalus spent a longer time in the ET, they foraged on land long and in almost all periods of test duration. They also prepared new nests in grass or under roots. Whereas in variants without natural structures (A, B and F) $N$. anomalus spent a short time in the ET, foraged less on land, and the food they found usually was transported by them to the NT. The similar relationships were found in $N$. fodiens. Furthermore, the higher was the structural differentiation of a given stretch of water bank, the longer $N$. fodiens foraged (Schröpfer 1985). Thus, the significance of natural structures as stimulants seems to be very probable. 
Second, the natural structures used in these experiments could provide a sufficient safe cover encouraging $N$. anomalus to forage longer and with higher success. Examples of foraging being more effective in covered than open places, or that open places are entirely omitted during foraging and other activities, are known from studies on different animals, also on small mammals (eg Bąkowski and Kozakiewicz 1988, Kaufman and Kaufman 1990, Clark and Kaufman 1991). In shrews, utilization of natural covers and shady places during foraging were described eg in Sorex palustris, S. cinereus (Conaway 1952, Buckner 1970) and several Sorex species from Siberia (Yudin 1962). N. anomalus are famous for their shyness, high excitability and susceptibility to stress of unknown surroundings (Michalak 1982, Krushinska and Pucek 1989, Krushinska and Rychlik 1993). In the present experiments the following facts indicate that $N$. anomalus felt discomfort in uncovered sites: (1) in variants without natural structures their foraging on land consisted usually in short-term (a few seconds) and frequently interlaced with events of ground investigations and staying in one of the 3 hiding-places in the terrestrial part of the ET, (2) $N$. anomalus rarely ate food where they found it. Usually they retreated to feed in the nest (in the terrarium NT), in hiding-places or under the cover of dense grass. This is a common characteristic of predatory mammals, as well as shrews. For example, Sorex unguiculatus and $S$. caecutiens usually took the food they found to the shelter or the nest and then ate it there; only occasionally did they eat the food at the place where they found it (Yoshino and Abe 1984). N. fodiens also ate most food in covered places (Schröpfer 1985, present study). Therefore, it seems to be very probable that in variants $\mathrm{E}$ and $\mathrm{D}$ foraging duration and success of $N$. anomalus were long and high at least partly because of safe conditions created by natural structures, and in remaining variants they were low because of stress of open field.

In all variants (except W) $N$. anomalus found food as early as the first quarter after their entering the terrarium ET. This suggests that, regardless of changes used in particular variants, foraging on land never became too difficult for $N$. anomalus, detainnig them from the first location of food portions. However, when the quantity of food placed on land was reduced (variant $B$ ), the foraging success of $N$. anomalus was surprisingly low. It equaled $41.6 \%$ of food portions found, although the probability of finding $100 \%$ from 13 food portions given on land was higher than eg in variant $D$ when 38 food portions were offered. Moreover, $N$. anomalus shortened foraging activity in the variant $B$. These results are consistent with findings on the susceptibility of different Soricidae to short-term changes in food availability (Hanski 1985): just after the decrease of food availability, the large shrews (to which $N$. anomalus can be included) reduce their activity, whereas small shrews intensify it. Hanski (1985) explains this by the fact that large shrews possess larger body energetic reserves and can wait through short periods of difficult foraging (eg bad weather). Foraging in variant B was probably too difficult for $N$. anomalus (it had the lowest foraging efficiency in this 
variant) and they ceased it. The mechanisms of foraging breaking and patch choosing are quite well-known in rodents (eg Brown 1988, Brown and Mitchell 1989) and they were also investigated in shrews [Hanski 1989, (Landén 1989) cit. in Saarikko 1989, Barnard and Brown 1985a, b, 1987, Barnard et al. 1985]. Usually the foraging in a given patch ceases when the food density within the patch decreases below a certain threshold called "the giving up density". It was found that the level of this threshold depends on current energy requirements and predictability of food resources within the patch (Barnard and Brown 1985a, 1987, Barnard et al. 1985), presence of competitors (Barnard and Brown 1985b), habitat conditions (open or covered area) and predation risk (Brown 1988), distance to the next food patch (Landén 1989), and individual variation (Hanski 1989).

\section{Differences in foraging between $N$, anomalus and $N$. fodiens obtained in the present experiments}

Because of a small number of $N$. fodiens tested by Ruthardt (1990) the interspecific differences shown in "Results" could not be supported statistically (with an exception of variants $\mathrm{A}$ and $\mathrm{W}$ ). Therefore, they will be discussed as tendencies which require a verification in future investigations of a larger group of shrews.

$N$. anomalus and $N$. fodiens displayed great differences in both behaviour and success of foraging in water. $N$. fodiens significantly longer than $N$. anomalus foraged in and under water when food was available only under water (variant W). As a result, $N$. fodiens found on average $19.4 \%$ of food portions placed under water, whereas $N$. anomalus did not find food at all under these conditions. $N$. fodiens foraged in water considerably longer and more successfully than $N$. anomalus also in all other variants. Resulting from these facts is the conclusion that $N$. fodiens forage in deep (>10 $\mathrm{cm}$ ) water (aquatic mode of foraging) also in the wild. This conforms to the previous knowledge of their feeding habits.

According to the model of foraging in a one-dimensional habitat (eg along water banks), animals visit many times the ample feeding grounds (ie with prey availability above certain threshold), and omit patches with prey availability below this threshold (Arditi and Dacorogna 1988). The route taken by a semiaquatic predator during searches for aquatic prey should be composed of long and straight travelling stretches along water banks, and relatively long stops in chosen patches. It was observed in the present tests that $N$. fodiens, after detection of a food clump under water, dived many times for successive food portions taken from the same site. $N$. fodiens observed in the wild (Schloeth 1980, Illing et al. 1981, D. Cantoni, pers. comm.) dived repeatedly in the same place of the stream or river. Moreover, the results of Schröpfer's (1985) laboratory experiments suggest that, in searching for good feeding grounds, these water shrews do not rummage through randomly visited sites, but they purposely search for sites with adequate water depth, steep slopes of water-side, and water-bank line rich in structures and sheiters. On the other hand, aquatic invertebrates which are food for $N$. fodiens are distributed in 
a cumulative way in fresh inland waters (eg Ruthardt 1990, DuPasquier and Cantoni 1992). The same is true as to distribution of fish- and frog-spawn, shoals of fry, and tadpoles (L. Rychlik, pers. obser.). All this leads to the conclusion that the strategy of searching for aquatic prey in $N$. fodiens is consistent with the above mentioned model of foraging in one-dimensional habitat (Arditi and Dacorogna 1988). This strategy is an adaptation to exploit clumped food resources and it is distinctly different from the strategy of the "random searching pattern" used in searching for dispersed terrestrial prey.

Both species of water shrews foraged longer and more successfully on land than in water. When foraging on land, $N$. fodiens rooted in grass less than $N$. anomalus. This suggests that in the wild $N$. fodiens may search for food among terrestrial vegetation to the lower degree than $N$. anomalus. On the other hand, $N$. fodiens rooted in soil more than $N$. anomalus. Thus, it seems that $N$. fodiens may more suecessfully than $N$. anomalus dig out prey from the ground (hypogeal foraging). Since $N$. fodiens are larger than $N$. anomalus (Pucek 1984, Innes 1994), the last conclusion conforms to the rule presented by Churchfield and Sheftel (1994) that ability of shrews to dig out food from the ground increases with the increase of shrews' body size.

Behaviour and success of foraging on land were in $N$. fodiens less influenced by natural structures than in $N$. anomalus. This result is in agreement with findings from Krushinska and Pucek (1989) who suggest higher resistance of $N$. fodiens to the stress of open field. This resistance surely gives some advantages to animals, which during foraging, have to swim on the open water surface and cross over uncovered muddy beaches and islets which are frequent along eg little forest creeks. $N$. fodiens also live on mountain streams and rivers with banks strewn with stones, gravel and sand, but with poor vegetation (Spitzenberger 1980). The weaker influence of terrestrial structures on foraging of $N$. fodiens may also suggest that this species is adapted to forage mainly in such habitats where there are no terrestrial structures, ie in water. This is consistent with lower preference to forage on land in $N$. fodiens than in $N$. anomalus found in the present experiments.

Similarly to $N$. anomalus, the success and efficiency of foraging on land were in $N$. fodiens usually higher when food on land was randomly dispersed than when it was clumped. This suggests that during epigeal foraging $N$. fodiens also use random searching pattern. This discussion leads to the more general conclusion that both species can successfully use epigeal and probably hypogeal foraging modes, but only $N$. fodiens are able to forage in aquatic mode.

Published data on differences in foraging between $N$. anomalus and $N$. fodiens

Many common opinions on $N$. anomalus [eg $N$. anomalus are everywhere connected to water and prefer fast-flowing, non-freezing water courses with steep rocky banks; their diet includes, among others, spawn, fish and frogs (Gureev 
1971, 1979); or the food of $N$. anomalus comprises insects, snails, crustaceans, frog-spawn, fry, small fish, frogs, and worms (Görner and Hackethal 1987)] have little evidence. Reliable data on the diet of $N$. anomalus are very scarce and lead to rather contradictory conclusions: the diet of $N$. anomalus may be composed mostly of aquatic prey (up to $90 \%$; Niethammer 1977, 1978), mostly of terrestrial prey (Kuvikova 1987), or only of terrestrial prey (Kuvikova 1985a, Ramalhinho 1995).

N. anomalus caught live crustaceans of genera Gammarus and Asellus as well as small fish (sticklebacks, roaches) in containers with water $3.5 \mathrm{~cm}$ deep (Jancewicz 1995, Rychlik and Jancewicz 1996). So, in these conditions, shrews did not have to dive for preys. In the wild $N$, anomalus ate few (much less than $N$. fodiens) larvae of Simuliidae and Ephemeroptera, which usually live under stones lying in sites with strong water flow (Niethammer 1977, 1978). Typical aquatic animals (Amphipoda, Isopoda, larvae of Trichoptera, Plecoptera, and Odonata), found in the diet of $N$. anomalus, can be caught in shallow water. Non-aquatic but connected to wet habitat animals (Gastropoda, imago of Trichoptera) could be caught during foraging along the water-line and/or in muddy and slimy grounds near natural waters. According to Niethammer (1977, 1978), when the water level in streams was high, the proportion of aquatic prey in the $\operatorname{diet}$ of $N$. anomalus was lower. All this suggests that $N$. anomalus forage mainly in shallow water. On the other hand, there are at least several shrew species known, which forage in the wild, in shallows and in muddy ground along bank-lines, but not in deep water. Spencer-Booth (1963), Pernetta (1973) and Churchfield (1988, 1990) describe Crocidura suaveolens, and Stewart et al. (1989) - Sorex cinereus, which live on sea-shores, forage along water-line, and catch littoral Amphipoda. Cryptotis parva prey on Isopoda and mollusces (Hamilton 1944, Davis and Joeris 1945), and Sorex bendirit on mollusces, ephemeropteran nymphs and insect larvae (Whitaker and Maser 1976) foraging on beaches and coastal salt-marshes. The foraging in shallow water (up to $5 \mathrm{~cm}$, where active diving is not needed) and in slime and mud is not a typical aquatic mode of foraging. Therefore, I propose to distinguish a new category: wading foraging mode. And hence, instead of classifying $N$. anomalus as the species which use mainly aquatic foraging mode (Churchfield 1990), N. anomalus (and other shrews foraging in this way) should be categorized to this new class. Thus, $N$. anomalus are able to use efficiently the wading, epigeal and probably hypogeal foraging, but not the aquatic foraging mode in deep water.

Presently, it is accepted that aquatic prey compose at least $50 \%$ of the diet of N. fodiens (Niethammer 1978, Churchfield 1984, Kuvikova 1985b, DuPasquier and Cantoni 1992, Castién 1995). Their share may reach $95 \%$ of the diet (Niethammer 1978, DuPasquier and Cantoni 1992). The high ability of this species to forage in water is certified by many reports (Buchalczyk and Pucek 1963, Pernetta 1976b, Wolk 1976, Kraft and Pleyer 1978, Illing et al. 1981) of aquatic vertebrates in the diet of wild $N$. fodiens. Their hunting on small fish were frequently observed in 
captivity (Lorenz 1952, Cranbrook 1959, Hawkins and Jewell 1962, Schröpfer 1985, Ruthardt and Schröpfer 1985, Rychlik and Jancewicz 1996).

$N$. fodiens prefer to forage in water not exceeding $30 \mathrm{~cm}$ of depth (Lardet 1987, Vogel et $a l$., in press). Swimming and diving make only $5 \%$ of their daily activity (IIling et al. 1981). However, during foraging $N$. fodiens dive frequently and to the considerable depths. For example, wild shrews dived 75 times during 85 minutes to the depth of $0.5-2.0 \mathrm{~m}$ or 80 times during 24 minutes to the depth $30 \mathrm{~cm}$ (Schloeth 1980). In captive $N$. fodiens, the mean number of dives per day was 546 , with maximum 890 dives. Mean catching success (number of Gammarus sp. individuals caught per 1 dive) ranged under different experimental conditions between 0.44 and 1.40 (Vogel et al., in press). These authors also tested the ability of $N$. fodiens to diving in a transparent tube filled with water and placed at an angle 30 to horizon. $N$. fodiens dived to the depth of $5.0 \mathrm{~m}$ (vertically ca $2.6 \mathrm{~m}$ ), and, as the authors believe, this is not their physiological limit of diving capacity. Although the average duration of one stay under water is short: $4 \mathrm{~s}$ (Churchfield 1985) or $12 \mathrm{~s}$ (Vogel et al., in press), Schloeth (1980) observed in the wild, a $N$. fodiens which dived continuously for $24 \mathrm{~s}$. While diving, $N$. fodiens are able to utilize (for breathing) air-bubbles located under leaves or other concave objects submerged in water ( $\mathrm{P}$. Vogel, pers. comm.).

Ruthardt and Schröpfer (1985) described in $N$. fodiens two different strategies of hunting under water according to prey type. Pelagic fish (sticklebacks, bleaks, Leucaspius delineatus) are caught by $N$. fodiens during straight-line swimming in upper and middle layers of water. After a shoal of small fish is detected, $N$. fodiens make sudden movements of head and bends of body and they try to catch a fish by its tail or back. Whereas bottom fish (tenches, gudgeons) and benthic invertebrates are caught during "creeping" on the bottom and "feeling" it with their snout (in German: Gründeln). During this hunting, shrews frequently change direction of movement and stop. They dig then with their snout and fore-feet at the bottom, squeeze under stones and other objects lying on the bottom, and turn them up. This results in thorough searching of pond's bottom. The caught prey is always taken on land and eaten here. According to the same authors, during foraging in water, $N$. fodiens never search for and catch prey on the water surface, but always during diving under water. Ruthardt and Schröpfer (1985) report also that $N$. fodiens usually dived for $3-6 \mathrm{~s}$, and that their movement speeds were: on land $30 \mathrm{~cm} / \mathrm{s}$, swimming $-40 \mathrm{~cm} / \mathrm{s}$, diving $-50 \mathrm{~cm} / \mathrm{s}$.

Thus, wild $N$. fodiens hunt on many typical aquatic animals, also those living in water $\geq 10 \mathrm{~cm}$ deep and far from banks. This, of course, means that they use the aquatic foraging mode. Eating typical terrestrial prey (eg Coleoptera, Diplopoda) proves the usage of the epigeal and hypogeal foraging modes. In fact, it was recently demonstrated on the basis of diet composition that $N$. fodiens obtained ca $57 \%$ of food from aquatic foraging, $27 \%$ was epigeal and $16 \%$ was hypogeal (Churchfield 1994). However, the diet of $N$. fodiens also comprises many organisms living in wading zone. Therefore, $N$. fodiens also uses wading foraging mode. 


\section{Interspecific competition for food and microhabitat preferences}

It was shown that, if geographic ranges, macrohabitat preferences and diets of some shrew species overlap, then these species prefer different microhabitats (Hawes 1977, French 1984, Neet 1989, Neet and Hauser 1990). For the two water shrew species, three microhabitats: deep water, wading zone and ground of terrestrial habitats neighbouring waters should be considered as the main potential sites of foraging. Differences in foraging behaviour (found in the experiments) and, related to them, utilization of partly different food resources should result in different microhabitat preferences. It can be proposed that: $N$. fodiens, being strongly dependent on aquatic prey, should prefer sites with direct access to deep water. $N$. anomalus, with reduced aquatic foraging ability and less dependent on typical aquatic prey, should prefer sites wet and with access to shallow water, but covered with dense vegetation (Fig. 8).

There is evidence for such microhabitat preferences of $N$. fodiens. Home ranges of $N$. fodiens are usually established as narrow strips along waters suitable for diving (Illing et al. 1981, van Bemmel and Voesenek 1984, Lardet 1987, 1988, Cantoni 1990, 1993). These shrews are active close by water (Lardet 1988), which is supported by the fact that $94 \%$ of them were trapped at the water's edge, and a remaining $6 \%$ some $0.5 \mathrm{~m}$ from water (van Bemmel and Voesenek 1984). Niethammer (1977, 1978) and Voesenek and van Bemmel (1984) found that dominating adult individuals of $N$. fodiens displaced conspecific juveniles and individuals of $N$. anomalus from optimal places with diversified bank and access

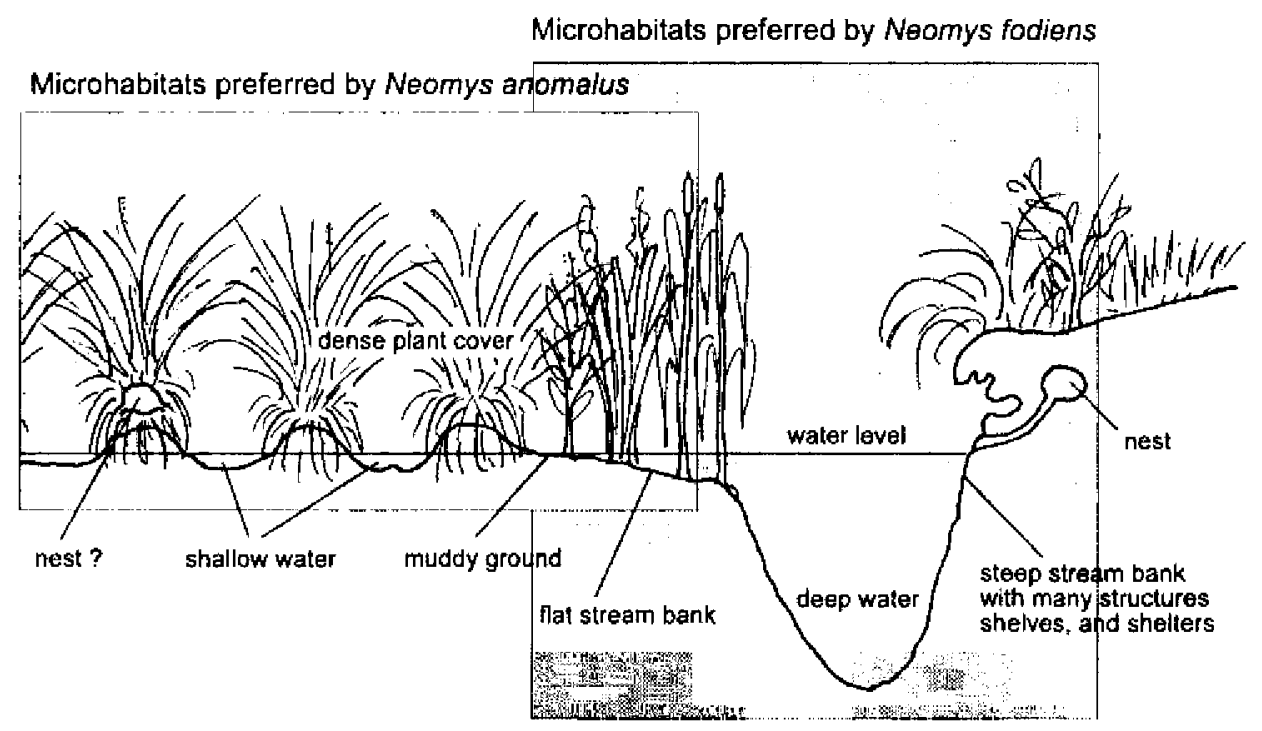

Fig. 8. Microhabitat preferences in Neomys anomalus and Neomys fodiens - a prediction based on the results of this study and literature data. 
to deep ( $>25 \mathrm{~cm}$ ) water. This intra- and interspecific competition for direct access to deep water distinctly shows the strong microhabitat preferences of $N$. fodiens.

Some information on $N$. anomalus is also available. In Czech Republic, $N$. anomalus preferred moist and wet habitats (such as marshes, moist meadows, littoral zones of fishponds, and alluvials of rivers and streams) with dense cover of hygrophilous plants. They were trapped here 3 times more frequently than $N$. fodiens. On stream banks covered with dense vegetation the trapping ratio of the two species was similar. And along stream and river banks without sufficient vegetation cover $N$. anomalus were trapped 5 times less frequently than $N$. fodiens (Anděra 1993, 1995). On banks of the Neusiedler lake, $N$. fodiens occupied sites with access to open water, whereas $N$. anomalus used wet and periodically flooded sites (Bauer 1960 cit. in Spitzenberger 1990). In Portugal, N. anomalus preferred wet meadows with dense vegetation cover and most specimens were trapped at considerable distance from water. Moreover, no specimen was captured in the middle or on the border of the water courses (Ramalhinho 1995 and pers. comm.). These differences may result from the displacement of $N$. anomalus to suboptimal places (what was suggested by Niethammer 1977, 1978), but they can also be an indication of natural microhabitat preferences of these species, which are unrelated to interspecific interactions. Although such preferences of $N$. anomalus as proposed in Fig. 8 seem to be very possible, further extensive studies are still needed.

Extending their trophic niche to aquatic prey, $N$. fodiens can exploit the twice as large a biomass of food resources than Sorex araneus and $S$. minutus which foraging only on land. This doubtless diminishes the competition for food between these species (Churchfield 1984). However, $N$. fodiens do not feed exclusively on aquatic prey due to high energetic costs of their capturing and relatively low costs of capturing of terrestrial prey (Churchfield 1985, Spitzenberger 1990). Therefore, for example, among shrews co-existing around water-cress beds in England, the diet of $N$. fodiens still overlapped by $44 \%$ with $S$. araneus, and even by $36 \%$ with S. minutus (Churchfield 1984), which are specialized in foraging on the ground surface and lower parts of plants (Butterfield et al. 1981, Ellenbroek 1990).

On the other hand, the proportion of aquatic prey in the diet of water shrews fluctuates considerably. The main factor causing these fluctuations are changes in availability of aquatic and terrestrial prey. This statement is supported by the following observations: (1) aquatic prey composed more than 95\% of the diet of $N$. fodiens in spring, when there were large clumps of large prey in the river; (2) the proportion of aquatic prey in the diet of $N$. fodiens was the lowest, and that of terrestrial prey the highest in autumn, when the biomass and energetic contents of benthic invertebrates were the lowest (DuPasquier and Cantoni 1992); (3) aquatic prey composed only $33 \%$ of the diet, when only small aquatic invertebrates in small quantities were available (Churchfield 1984). In the present study it was similar: $N$. fodiens took most food under water when its availability under water was the highest (variant $D$ ) and/or its availability on land was the lowest (variant W). 
The other factor causing the fluctuations in diet is the pressure of competitors. For example, under low pressure of terrestrial competitors $N$. fodiens should exploit more terrestrial food resources. It can be accepted that changes in the degree of overlap of the diets reflect changes in the current intensity of the competition for food between $N$. fodiens and $N$. anomalus, as well as other shrews co-existing with them around inland waters: Sorex alpinus, S. araneus, S. coronatus, S. minutus (Spitzenberger 1990). Therefore, the trophic competition between $N$. fodiens and $N$. anomalus will increase under low availability of aquatic prey, and it will decrease under high one. Some changes in the overlap of the diets were observed by Niethammer $(1977,1978)$. The diet overlap was low under high water level in streams, ie when availability of aquatic prey was high only for $N$. fodiens, whereas it was high when water level was lower. The least overlap $24 \%$ of aquatic prey in food of $N$. anomalus and $74 \%$ in $N$. fodiens - was in the year of the lowest water level. From these results Niethammer (1978) concluded that under low availability of aquatic prey the interspecific competition for food was stronger and $N$. fodiens displaced $N$. anomalus into suboptimal places. Unfortunately, the sample size in those investigations was rather small, the analysis of aquatic prey availability was made only for the last year of the 3-year-study period, and the analysis of terrestrial prey availability was not made at all.

If $N$. anomalus can forage on land very successfully (results of the present study), why is it that they do not occur far from water (which was clearly demonstrated by Dehnel 1950)? In all terrestrial macrohabitats of Białowieza Primeval Forest, in which $N$. anomalus, $N$. fodiens and $S$. araneus co-exist, $S$. araneus dominated numerically and $N$. anomalus were the rarest (Aulak 1970, Z. Pucek, pers. comm.). High density of $S$. araneus and their foraging on land suggest that this species is a strong competitor of $N$. anomalus (and also of $N$. fodiens) for stricte terrestrial prey. This means that the life strategy with wading foraging and exploitation of food resources occurring in wading zone (ie in shallow water and muddy grounds of banks and wet habitats) is the only vacant trophic niche for $N$. anomalus, between niches of $S$. araneus and $N$. fodiens. In mud, peat and other wet grounds are characterized by the absence of earthworms [(Svendsen 1957, Standen 1979) cit. in Butterfield et al. 1981], which are the most important component of the diet of $S$. araneus (eg Churchfield 1984). Therefore, these habitats should be avoided by this species during foraging. On the other hand, $N$. anomalus are usually several times less numerous than $N$. fodiens. This indicates that the niche of $N$. anomalus is very narrow and they still undergo a strong pressure by $N$. fodiens.

There are many areas where $N$. fodiens and $S$. araneus co-exist without $N$. anomalus, despite the fact that these places are within the geographic range and preferred macrohabitats of $N$. anomalus. Besides historical reasons, there are at least two possible explanations for this: (1) In these areas the availability of aquatic prey is low, so $N$. fodiens forage more in wading zones and on land, and 
displace $N$. anomalus from their niche. $N$. fodiens dominate behaviourally over N. anomalus (Krushinska and Pucek 1989, Krushinska and Rychlik 1993, Krushinska et al. 1994), so, such a displacement is possible. (2) In these areas the aquatic habitat turns directly into terrestrial habitat, without transitional wading zone (eg deep streams or rivers flowing through meadows). In such conditions $S$. araneus displace $N$. anomalus. However, these ideas need verification in future field studies.

\section{Conclusions}

(1) These laboratory investigations of $N$. anomalus and $N$. fodiens indicated clear differences in the natural foraging behaviour of these species.

(2) N. anomalus are unable to forage successfully in deep water, but they forage effectively on land. However, the exploitation of food resources from the wading zone (shallow water and muddy ground along fresh-water courses and ponds) and the use of the wading foraging mode seem to be the only vacant niche for this species, between niches of $N$. fodiens and stricte terrestrial shrews (Fig. 8).

(3) $N$, anomalus search for food among roots and lower parts of plants, as well as dig food out from the ground. They require dense cover of vegetation for successful foraging.

(4) $N$. fodiens are able to forage successfully and effectively on land, but they display a clear tendency to forage in deep (>10 cm) water (Fig. 8), where they capture a great part of their prey. It seems that during foraging on land $N$. fodiens do not search intensively for food among terrestrial plants, and the lack of natural structures and cover disturbs their foraging to a lower degree than in $N$. anomalus.

(5) Trophic niches of $N$. anomalus and $N$. fodiens may be well separated, allowing syntopic occurence of these two species.

(6) None of the 3 hypotheses presented in the "Introduction" can be rejected.

Acknowledgements: I am deeply grateful to Dr M. Ruthardt for her permission to use the results of her studies in this paper and for her great help in fixing all methodological details related to recording and analysis of the data. Prof $Z$. Pucek enabled me to carry out this study as well as helped during the analysis of the data and writing of the text. Prof $R$. Schröpfer rendered me access to his apparatus, laboratory and research subsidiaries. I also thank him very much for his essential guidance and all organizing help during the experiments in Osnabrück. I thank Professors S. Churchfield, R. Schröpfer, P. Vogel, and J. Weiner for their comments on an earlier draft of this manuscript. Dr B. Jędrzejewska and Dr W. Bogdanowicz helped in the statistical analysis of the results. A. Schwegmann helped in preparation of all apparatus used in the experiments. S. Buszko and A. Arasim helped in the trapping of animals. A. Buszko and E. Kunkel helped in keeping animals in captivity. H. Potts kindly corrected the English text. I wish to express my special acknowledgements to $\mathrm{B}$. Klenner-Fringes for her comprehensive help given to me during my stay in Osnabruck, and to M. Rychlik for her help during the whole study period.

The realization of this study was possible thanks to financial assistance awarded to me by the University of Osnabrück and the Deutscher Akademischer Austauschdienst (in the form of 10-month-scholarship for the experimental part of the study) and by the Polish State Committee for Scientific Research. 


\section{References}

Andéra M. 1993. Distribution of the Miller's water shrew (Neomys anomalus) in Czechoslovakia. Folia Musei Rerum Naturalium Bohemiae Occidentalis, Zoologica 37: 1-37.

Andéra M. 1995. The status and conservation needs of the Miller's water shrew (Neomys anomalus) in the Czech Republic. IIn: Proceedings of the "Seminar on the biology and conservation of European desmans and water shrews (Galemys pyrenaicus, Desmana moschata, Neomys spp.), Ordesa, Spain, 7-11 June 1995]. Council of Europe, Strasbourg, T-PVS (95) 32: 41-43.

Arditi R. and Dacorogna B. 1988. Optimal foraging on arbitrary food distributions and the definition of habitat patches. American Naturalist 131: 837-846.

Aulak W. 1970. Small mammal communities of the Białowieża National Park. Acta Theriologica 15: $465-515$.

Bąkowski C. and Kozakiewicz M. 1988. The effect of forest road on bank vole and yellow-necked mouse populations. Acta Theriologica $33: 345-353$.

Barnard C. J. and Brown C. A. J. 1985a. Risk-sensitive foraging in common shrews (Sorex araneus). Behavioral Ecology and Sociobiology 16: 161-164.

Barnard C. J. and Brown C. A. J. 1985b. Competition affects risk-sensitivity in foraging shrews (Sorex araneus). Behavioral Ecology and Sociobiology 17: 379-382.

Barnard C. J. and Brown C. A. J. 1987. Risk-sensitive foraging and patch residence time in common shrews, Sorex araneus L. Animal Behaviour 35: 1255-1257.

Barnard C. J., Brown C. A. J., Houston A. 1. and McNamara J. M. 1985. Risk-sensitive foraging in common shrews: an interruption model and the effects of mean and variance in reward rate. Behavioral Ecology and Sociobiology 18: 139-146.

Bemmel A. C. van and Voesenek L. A. C. J. 1984. The home range of Neomys fodiens (Pennant, 1771) in the Netherlands. Lutra 27: 148-153.

Borowski S. and Dehnel A. 1952. [Materials on biology of Soricidae]. Annales Universitatis Mariae Curie-Sktodowska, Sectio C 7: 305-448. [In Polish with Russian and German summaries]

Brewster R. W. 1966. Hunting behaviour of the water shrew, Essex Nature 31: 377-378.

Brown J. S. 1988. Patch use as an indicator of habitat preference, predation risk, and competition. Behavioral Ecology and Sociobiology 22: 37-48

Brown J. S. and Mitchell W. A. 1989. Diet selection on depletable resources. Oikos 54: 33-43

Buchalezyk A. 1972. Seasonal variations in activity of shrews. Acta Theriologica 17: 221-243.

Buchalczyk T. and Pucek Z. 1963. Food storage of the European water shrew Neomys fodiens (Pennant, 1771). Acta Theriologica 7: 376-379.

Buckner C. H. 1970. Direct observation of shrew predation on insect and fish. Blue Jay 28: 171-172.

Butterfield J., Coulson J. C. and Wanless S. 1981. Studies on the distribution, food, breeding biology and relative abundance of the pygmy and common shrews (Sorex minutus and $S$. araneus) in upland areas of northern England. Journal of Zoology, London 195: 169-180.

Cantoni D. 1990. Etude en milieu naturel de l'organisation sociale de trois especes de musaraignes, Crocidura russula, Sorex coronatus et Neomys fodiens (Mammalia, Insectivora, Soricidae). These de Doctorat, Universite de Lausanne, Lausanne: $1-157+5$.

Cantoni D. 1993. Social and spatial organization of free-ranging shrews, Sorex coronatus and Neonys fodiens (Insectivora, Mammalia), Animal Behaviour 45: 975-995.

Castien E. 1995. The diet of Neomys fodiens in the Spanish western Pyrenees. Folia Zoologica 44: $297-303$.

Churchfield J. S. 1979. A note on the diet of the European water shrew, Neomys fodiens bicolor. Journal of Zoology, London 188: 294-296.

Churchfield S. 1980. Subterranean foraging and burrowing activity of the common shrew. Acta Theriologica 25: $451-459$.

Churchfield S. 1984. Dietary separation in three species of shrew inhabiting water-cress beds. Journal of Zoology, London 204: 211-228. 
Churchfield S. 1985. The feeding ecology of the water shrew. Mammal Review 15: 13-21.

Churchfield S. 1988. Shrews of the British Isles. Shire Natural History 30; 1-24.

Churchfield S. 1990. The natural history of shrews. Christopher Helm, London: 1-192

Churchfield S. 1991. Niche dynamics, food resources, and feeding strategies in multispecies comrnunities of shrews. [In: The biology of the Soricidae. J. S. Findley and T. L. Yates, eds]. The Museum of Southwestern Biology, University of New Mexico, Albuquerque: 23-34.

Churchfield S. 1993. Foraging strategies of shrews: interactions between small predators and their prey. Symposia of the Zonlogical Society of London 65: 235-252.

Churchfield S. 1994. Foraging strategies of shrews, and the evidence from freld studies. [In: Advances in the biology of shrews. J. F. Merritt, G. L. Kirkland Jr and R. K. Rose, edsl. Special Publication of Carnegie Museum of Natural History No. 18, Pittsburgh: 77-87.

Churchfield S. and Sheftel B. I. 1994. Food niche overlap and ecological separation in a multi-species community of shrews in the Siberian taiga. Journal of Zoology, London 234: 105-124.

Churchfield S., Sheftel B. I., Moraleva N. V. and Shvarts E. A. 1997. Habitat occurrence and prey distribution of a multi-species community of shrews in the Siberian taiga. Journal of Zoology, London 241: $55-71$

Clark B. K. and Kaufman D. W. 1991. Effects of plant litter on foraging and nesting behavior of prairie rodents. Journal of Mammalogy 72: 502-512.

Conaway C. H. 1952. Life history of the water shrew (Sorex paltustris navigator). American Midland Naturalist 48: 219-248.

Cranbrook E. of. 1959. The feeding habits of the water-shrew, Neomys fodiens bicolor Shaw, in captivity and the effect of its attack upon its prey. Proceedings of the Zoological Society of London 133: 245-249.

Croin Michielsen N. 1966. Intraspecific and interspecific competition in the shrews Sorex araneus L. and S. minutus L. Archives Nérlandaises de Zoologie 17: 73-174.

Crowcroft P. 1957. The life of the shrew, Max Reinhardt, London: 1-166.

Crowcroft W. P. 1955. Notes on the behaviour of shrews. Behaviour 8: $63-80$.

Davis W. B. and Joeris L. 1945. Notes on the life-history of the little short-tailed shrew. Journal of Mammalogy 26: 136-138.

Dehnel A. 1950. Studies on the genus Neomys Kaup. Annales Universitatis Mariae Curie-Sklodowska, Sectio C 5: 1-63. [In Polish with Russian and English summaries]

DuPasquier A. and Cantoni D. 1992. Shifts in benthic macroinvertebrate community and food habits of water shrew, Neomys fodiens (Soricidae, Insectivora). Acta OEcologica 13: 81-99.

Ellenbroek F. J. M. 1990. An experimental analysis of interspecific competition in the shrews Sorex araneus L. and $S$. minutus L. (Soricidae, Insectivora). Ph D thesis, University of Leiden. H. Gianotten, Tilburg: 1-125.

Fox B. J. and Kirkland G. L. Jr. 1992. An assembly rule for functional groups applied to North American soricid communities. Journal of Mammalogy 73: 491-503.

French T. W. 1984. Dietary overlap of Sorex longirostris and $S$. cinereus in hardwood floodplain habitats in Vigo County, Indiana. American Midland Naturalist 11: 41-46.

Görner M. and Hackethal H. 1987. Säugetiere Europas. Neumann Verlag Leipzig, Radebeul: 66-67.

Grainger J. P. and Fairley J. S. 1978. Studies on the biology of the pygmy shrew, Sorex minutus, in the west of Ireland. Journal of Zoology, London 186: 109-141.

Greń J. 1982. [Mathematical statistics. Models and exercises]. Polish Scientific Publishers, Warsaw: 1-363. [In Polish]

Gureev A. A. 1971. IShrews (Soricidae) of the world faunal. Izdatiel'stvo "Nauka", Leningradskoe Otdelenie, Leningrad: 1-256. [In Russian]

Gureev A. A. 1979. [Insectivours (Mammalia, Insectivora). Hedgehogs, moles and shrews (Erinaceidae, Talpidae, Soricidae)|. Izdatiel'stvo "Nauka", Leningradskoe Otdelenie, Leningrad: 1-503. IIn Russiani

Hamilton W. J. 1944. The biology of the little short-tailed shrew Cryptotis parva. Journal of Mammalogy 25: 1-7. 
Hanski I. 1985. What does a shrew do in an energy crisis? (In: Behavioural ecology. R. M. Sibly and R. H. Smith, edsl. Symposia of the British Ecological Society, Blackwell, Oxford: 247-252.

Hanski I. 1989. Habitat selection in a patchy environment: individual differences in common shrews. Animal Behaviour 38: 414-422.

Hawes M. L. 1977. Home range, territoriality, and ecological separation in sympatric shrews Sorex vagrans and Sorex obscurus. Journal of Mammalogy 58: 354-367.

Hawkins A. E. and Jewell P. A. 1962. Food consumption and energy requirements of captive British shrews and the mole. Proceedings of the Zoological Society of London 138: 137-155.

Holling C. S. 1959. The components of predation as revealed by a study of the small mammal predation of European sawfly. Canadian Entomologist 41: 293-332.

Hutterer R. 1985. Anatomical adaptations of shrews. Mammal Review 15: 43-55.

Illing K., Illing R. and Kraft R. 1981. Freilandbeobachtungen zur Lebensweise und zum Revierverhalten der Europäischen Wasserspitzmaus, Neomys fodiens (Pennant, 1771). Zoologische Beiträge 27: 109-122.

Innes D. G. L. 1994. Life histories of the Soricidae: a review. [In: Advances in the biology of shrews. J. F. Merritt, G. L. Kirkland Jr and R. K. Rose, eds]. Special Publication of Carnegie Museum of Natural History No. 18, Pittsburgh: 111-136.

Jancewicz E. 1995. [Prey preferences of four shrew species co-habiting in wet habitats of the Białowieza Primeval Forest]. M Sc thesis, University of Agriculture, Warszawa: 1-44. [In Polish]

Kaufman D. W. and Kaufman G. A. 1990. Influence of plant litter on patch use by foraging Peromyscus maniculatus and Reithrodontomys megalotis. American Midland Naturalist 124: 195-198.

Kirkland $G, L$ Jr 1991. Competition and coexistence in shrews (Insectivora, Soricidae). [In: The biology of the Soricidae. J. S. Findley and T. L. Yates, eds]. Special Publication, The Museum of Southwestern Biology, University of New Mexico, Albuquerque: 15-22.

Kirkland G. L. Jr and Van Deusen H. M. 1979. The shrews of the Sorex dispar group: Sorex dispar Batchelder and Sorex gaspensis Anthony and Goodwin. American Museum Novitates 2675: 1-21.

Köhler D. 1993. On the learning of the position of underwater food sources by Neomys fodiens (Mammalia, Soricidae), Zoologischer Anzeiger 231: 73-81.

Köhler D. 1996. Umwegversuche mit tauchenden Wasserspitzmäusen (Neomys fodiens) (Mammalia: Soricidae). Bonner zoologische Beitràge 46: $315 \cdots 325$.

Kraft R. and Pleyer G. 1978. Zur Ernährungsbiologie der Europäischen Wasserspitzmaus, Neomys fodiens (Pennant, 1771), an Fischteichen. Zeitschrift fur Saugetierkunde 43: 321-330.

Krushinska N. L. and Pucek Z. 1989. Ethological study of sympatric species of European water shrews. Acta Theriologica 34: 269-285.

Krushinska N. L. and Rychlik L. 1993. Intra- and interspecific antagonistic behaviour in two sympatric species of water shrews: Neomys fodiens and $N$. anomalus. Journal of Ethology 11: 11-21.

Krushinska N. L., Rychlik L. and Pucek Z. 1994. Agonistic interactions between resident and immigrant sympatric water shrews: Neomys fodiens and $N$. anomalus. Acta Theriologica 39: $227-247$.

Krystufek B. and Petkovski S. 1989. Distribution of water shrews (gen. Neomys Kaup, 1829, Insectivora, Mammalia) in Macedonia. Fragmenta Balcanica 14: 107-116.

Kuvikova A. 1985a. The food of some species of the family Soricidae (Insectivora) in the alder forest of the Jursky sur wetland. Biológia (Bratislava) 40: 181-187. [In Slovak with English abstract]

Kuvikova A. 1985b. Zur Nahrung der Wasserspitzmaus, Neomys fodiens, in der Slowakei. Biológia (Bratislava) 40: 563-572.

Kuvikova A. 1987. Zur Nahrung der Sumpfspitzmaus Neomys anomalus Cabrera, 1907 (Insectivora, Soricidae) in der Slowakei. Lynx (Praha) 23: 55-62.

Kuznetzov V. I. 1972. On the ecology of Crocidura suaveolens and Diplomesodon pulchellum Licht. in the Kara Kum desert. Teriologiya I, Novosibirsk 1: 266-276. [In Russian with English summary] 
Lardet J.P. 1987. Contribution à l'étude de quelques aspects de la stratégie énergétique de la musaraigne aquatique, Neomys fodiens (Mammiferes, Insectivores). These de Doctorat, Faculté des Sciences de l'Université de Lausanne, Lausanne: 1-142.

Lardet J.-P. 1988. Spatial behaviour and activity patterns of the water shrew, Neomys fodiens in the field. Acta Theriologica 33: 293-303.

Lorenz K. Z. 1952. The taming of the shrew. IIn: King Salomon's ring. New light on animal ways. Lorenz K. Z., ed]. Methuen \& Co. Ltd., London: $92-113$.

Michalak I. 1982. Reproduction and behaviour of the Mediterranean water shrew under laboratory conditions. Säugetierkundliche Mitteilunenen 30: 307-310.

Neet C. R. 1989. [Evaluation of interspecific territoriality between Sorex araneus and S. coronatus in a zone of syntopy (Insectivora, Soricidae)]. Mammalia 53: 329-336.

Neet C. R. and Hausser J. 1990. Habitat selection in zones parapatric contact between the common shrew Sorex araneus and Millet's shrew S. coronatus. Journal of Animal Ecology 59: 235-250.

Niethammer J. 1977. Ein syntopes Vorkommen der Wasserspitzmäuse Neomys fodiens und Neomys anomalus. Zeitschrift für Säugetierkunde 42: 1-6.

Niethammer d. 1978. Weitere Beobachtungen über Wasserspitzmăuse der Arten Neomys fodiens und N. anomalus. Zeitschrift für Säugetierkunde 43: 313-321.

Pernetta IJ. C. 1973. The ecology of Crocidura suaveolens cassiteridum (Hintom) in a coastal habitat. Mammalia 37: 241-256.

Pernetta J. C. 1976a. Diets of the shrews Sorex araneus L. and Sorex minutus L. in Wytham grassland. Journal of Animal Ecology 45: 899-912.

Pernetta J. C. 1976b. A note on the predation of smooth newt, Triturus vulgaris by European water-shrew, Neomys fodiens bicolor. Journal of Zoology, London 179: 215-216.

Pernetta J. C. 1977. Anatomical and behavioural specialisations of shrews in relation to their diet. Canadian Journal of Zoology $55: 1442-1453$.

Pierce G. J. 1987. Search paths of foraging common shrews Sorex araneus. Animal Behaviour 35: $1215-1224$.

Pucek Z. (ed) 1984. |Keys to vertebretes of Poland. Mammals]. Polish Scientific Publishers, Warsaw: 74-80. [In Polish]

Ramalhinho M. G. 1995. Preliminary account of the biology of Neomys anomalus Cabrera, 1907 in Portugal. [In: Proceedings of the "Seminar on the biology and conservation of European desmans and water shrews (Galemys pyrenaicus, Desmana moschata, Neomys spp.), Ordesa, Spain, 7-11 June 1995|. Council of Europe, Strasbourg, T-PVS (95) 32: 63-66.

Ruthardt M. 1990. Ein öko-ethologischer Ansatz zur Erklärung der semiaquatischen Lebensweise der Wasserspitzmaus (Neomys fodiens Pennant, 1771). Dissertation zur Erlangung des Doktorgrades der Naturwissenschaften, Unjversität Osnabrück, Osnabrück: 1-251.

Ruthardt M. and Schröpfer R. 1985. Zum Verhalten der Wasserspitzmaus Neomys fodiens (Pennant, 1771) unter Wasser. Zeitschrift für angewandte Zoologie 72: 49-57.

Rychlik L. 1995. Differences in foraging behaviour between Neomys anomalus and $N$. fodiens. Ph D thesis, Polish Academy of Sciences, Mammal Research Institute, Białowieża: 1-71 + 35. IIn Polish with English summary]

Rychlik L. and Jancewicz E. 1996. [Differences in prey preferences of four shrew species co-habiting in wet habitats]. [In: Proceedings of the "Polish Theriological Conference - Puszczykowo "96", 23-26.05. 1996]. University of Poznań, Poznań: 24-25. [In Polish]

Saarikko J. 1989. Foraging behaviour of shrews. Annales Zoologici Fennici 26: 411-423.

Sawyer F. E. 1946. Further studies of the water shrew. Journal of Society for the Preservation of the Fauna of the Empire 54: 38-40.

Schloeth R. 1980. Freilandbeobachtungen an der Wasserpitzmaus Neomys fodiens (Pennant, 1771), im Schweizerischen Nationalpark. Revue suisse Zoolgie 87: 937-940.

Schropfer R. 1985. Ufergebundenes Verhalten und Habitatselektion bei der Wasserspitzmaus Neomys fodiens (Pennent, 1771). Zeitschrift für angewand te Zoologie 72: 37-48. 
Sheftel B. I. 1994. Spatial distribution of nine species of shrews in the central Siberian taiga. IIn: Advances in the biology of shrews. J. F. Merritt, G. L. Kirkland $J r$ and R. K. Rose, eds]. Special Publication of Carnegie Museum of Natural History No. 18, Pittsburgh: 45-55.

Spencer-Both Y. 1963. A coastal population of shrews (Crocidura suaveolens cassiteridum). Proceedings of the Zoological Society of London 140: 322-326.

Spitzenberger F. 1980. Sumpf- und Wasserspitzmaus (Neomys anomalus Cabera, 1907 und Neomys fodiens Pennant, 1771) in Österreich. Mittelungen der Abteilung für Zoologie der Landesmus Joanneum 9: 1-39.

Spitzenberger F. 1990. Gattung Neonys Kaup, 1829. [In: Handbuch der Säugetiere Europas. Insektenfresser-Herrentiere. Band 3/1. J. Niethamer and F. Krapp, eds]. Aula-Verlag, Wiesbaden: $313-374$

Stewart D. T., Herman T. B. and Teferi T. 1989. Littoral feeding in a high-density insular population of Sorex cinereus. Canadian Journal of Zoology 67; 2074-2077.

SYSTAT V5. 1992. Systat for Windows: Version 5 Edition. SYSTAT, Inc., Evanston, IL.

Terry C. J. 1981. Habitat differentiation among three species of Soret and Neurotrichus gibbsii in Washington. American Midland Naturalist 106: 119-125.

Tupikova N. V. 1949. [The diet and nature of daily cycle of activity of shrews from central region of U.S.S.R.]. Zoologicheskiï Zhurnal 28: 561-572. [In Russian]

Voesenek L. A. C. J. and Bemmel A. C. van. 1984. Intra- and interspecific competition in the water shrew in the Netherlands. Acta Theriologica 29: 297-301.

Vogel P., Bodmer C., Spreng M. and Aeschimann J. 1997. Diving capacity and foraging behaviour of the water shrew (Neomys fodiens). IIn: Behaviour and ecology of riparian mammals. N. Dunstone and M. L. Gorman, edsl. Symposia of the Zoological Society of London 71. (in press)

Whitaker J. O. Jr and Maser C. 1976. Food habits of five western Oregon shrews. Northwestern Scientist 50: 102-107.

Wolk K. 1976. The winter food of the European water-shrew. Acta Theriologica 21: 117-129.

Yoshino H. and Abe H. 1984. Comparative study on the foraging habits of two species of soricine shrews. Acta Theriologica 29: 35-43.

Yudin B. S. 1962. Ecology of shrews (genus Sorex) of western Siberia, USSR. (In: Problems on the ecology, zoogeography and systematics of animals. B. S. Yudin, ed]. Nauka, Moskow: 33-134.

Received 10 April 1997, accepted 16 October 1997. 